University of Montana

ScholarWorks at University of Montana

8-2006

\title{
How Transient Patches Affect Population Dynamics: The Case of Hypoxia and Blue Crabs
}

\author{
Craig A. Aumann \\ Lisa A. Eby \\ University of Montana - Missoula, lisa.eby@umontana.edu \\ William F. Fagan
}

Follow this and additional works at: https://scholarworks.umt.edu/wildbio_pubs

Part of the Life Sciences Commons

Let us know how access to this document benefits you.

\section{Recommended Citation}

Aumann, Craig A.; Eby, Lisa A.; and Fagan, William F., "How Transient Patches Affect Population Dynamics: The Case of Hypoxia and Blue Crabs" (2006). Wildlife Biology Faculty Publications. 26.

https://scholarworks.umt.edu/wildbio_pubs/26

This Article is brought to you for free and open access by the Wildlife Biology at ScholarWorks at University of Montana. It has been accepted for inclusion in Wildlife Biology Faculty Publications by an authorized administrator of ScholarWorks at University of Montana. For more information, please contact scholarworks@mso.umt.edu. 


\title{
HOW TRANSIENT PATCHES AFFECT POPULATION DYNAMICS: THE CASE OF HYPOXIA AND BLUE CRABS
}

\author{
Craig A. Aumann, ${ }^{1,3}$ Lisa A. Eby, ${ }^{2}$ and William F. Fagan ${ }^{1}$ \\ ${ }^{1}$ Department of Biology, University of Maryland, College Park, Maryland 20742 USA \\ ${ }^{2}$ Wildlife Biology Program, University of Montana, Missoula, Montana 59812 USA
}

\begin{abstract}
Transient low-oxygen patches may have important consequences for the population dynamics of estuarine species. We investigated whether these transient hypoxic patches altered population dynamics of the commercially important blue crab (Callinectes sapidus) and assessed two alternative hypotheses for the causal mechanism. One hypothesis is that temporary reductions in habitat due to hypoxia increase cannibalism. The second hypothesis is that crab population dynamics result from food limitation caused by hypoxiainduced mortality of the benthos. We developed a spatially explicit individual-based model of blue crabs in a hierarchical framework to connect the autoecology of crabs with the spatial and temporal dynamics of their physical and biological environments. Three primary scenarios were run to examine the interactive effects of (1) hypoxic extent vs. static and transient patches, (2) hypoxic extent vs. prey abundance, and (3) hypoxic extent vs. cannibalism potential. Static patches resulted in populations limited by egg production and recruitment whereas transient patches led to populations limited by the effects of cannibalism and patch interactions. Crab survivorship was greatest for simulations with the largest hypoxic patches which also had the lowest prey abundance and lowest crab densities. In these simulations, nearly all crab mortality was accounted for by aggression, not starvation. In addition, increased prey abundance had little influence on crab abundance and dynamics, and massive reductions in prey abundance $(>50 \%)$ were necessary to decrease crab abundance, survival, and egg production. Our analyses suggest that cannibalism coupled with decreased egg production determined key aspects of crab demography. Specifically, decreased cannibalism potential resulted in a food-limited crab population with long development times and high adult crab densities whereas increased cannibalism potential led to low adult crab densities with higher individual egg production rates. Our analyses identified several key knowledge gaps, including the nature of crab-crab cannibalism and the role of refuges from predation. Several experiments are suggested to test model predictions and to improve understanding of ecosystem-population linkages for this estuarine species.
\end{abstract}

Key words: Callinectes sapidus; cannibalism; emergent property; food limitation; hypoxia; individualbased model; population dynamics; scaling.

\section{INTRODUCTION}

Ecologists are increasingly turning their attention to spatial problems, particularly issues of spatial heterogeneity. Much research to date has focused on what can be described as "static" patches, situations where the geometry, location, and/or quality of patches is effectively constant compared to the pace of the dynamics taking place within or among patches. This focus on static patches is especially true of population and community ecology, where classical metapopulation theory (Hanski and Gilpin 1997), competition-colonization models (Tilman et al. 1994, 1997), and theoretical approaches to nature reserve design (Pressey et al. 1993, 1997) all typically involve patches that are in most ways

Manuscript received 18 January 2005; revised 2 February 2006; accepted 6 February 2006. Corresponding Editor: J. R. Bence.

${ }^{3}$ Present Address: Department of Biological Sciences, University of Alberta, Edmonton, Alberta T6G 2E9 Canada. E-mail: caumann@ualberta.ca static. In contrast, landscape ecology has historically embraced problems with longer timescales and consequently has adopted modeling frameworks, such as hierarchical patch dynamics (Wu and Loucks 1995), in which patches or certain patch traits have finite lifetimes.

Studies of habitat demography (e.g., Pain and Levin 1981, Caswell and Cohen 1991, Gyllenberg and Hanski 1997, Johnson 2000), are also partly motivated by the recognition that many ecological systems feature "transient" patches where patch characteristics change quickly relative to the timescale of the population or community involved. For example, rocky intertidal habitats feature short-lived patches (e.g., disturbanceinduced gaps in mussel beds) in which interspecific interactions determine the rate of patch closure (Paine and Levin 1981). Likewise in terrestrial systems, forest clearcuts in which patch quality degrades with time can constitute transient patches in some butterfly metapopulations (Wahlberg et al. 2002); as can gravel bars for grasshoppers (Stelter et al. 1997), mowed agricultural 
meadows for the white stork (Johst et al. 2001, 2002), and drought dynamics for the Florida snail kite (Mooij et al. 2002). Such disparate examples highlight that transient patches are of potentially broad relevance to population dynamics.

Another good example of transient habitat patches involves hypoxic water (dissolved oxygen concentrations below $2 \mathrm{mg} / \mathrm{L}$ ) in estuaries (Diaz and Rosenberg 1995), where large patches (hundreds to thousands of meters across) of poor (and often lethal) quality habitat form quickly and persist for only a matter of days or weeks (Selberg et al. 2001, Buzzelli et al. 2002). The unique conditions posed by such biotically hostile transient patches present major challenges to resident species that respond differently to patch characteristics, leading to altered species interactions (e.g., Breitburg et al. 1997).

Transient hypoxic patches constitute an issue of increasing concern to ecologists and resource managers alike (e.g., Diaz and Rosenberg 1995, Luettich et al. 1999, Craig et al. 2001) because human impacts are altering the quantity and quality of estuarine habitats through eutrophication and subsequent hypoxia. In Atlantic estuarine systems that experience seasonal or intermittent hypoxia, large blue crabs (Callinectes sapidus Rathbun) migrate from hypoxic zones, generally located deeper in the estuary, to shallower, more oxygen-rich nearshore areas (Lowery and Tate 1986, Pihl et al. 1991, Das and Stickle 1994). In the Neuse River estuary in North Carolina, temporary habitat loss for blue crabs due to hypoxic avoidance has reached $42 \%$ (Buzzelli et al. 2002). Crabs are highly cannibalistic with large crabs (14-16 cm carapace width) accounting for very high rates of juvenile mortality $(40-90 \%$ in Chesapeake [Hines and Ruiz 1995], $>85 \%$ in Alabama [Spitzer et al. 2003]), with somewhat lower rates farther north (Heck and Coen 1995). Thus, temporary habitat loss, which forces large crabs into areas typically occupied by small crabs, could have important consequences for population dynamics. In addition, the decline in the benthic assemblage biomass dominants $M$. balthica and M. mitchelli due to hypoxia has reached 90$100 \%$ over $38 \%$ of the Neuse (Buzzelli et al. 2002). Because these clams are also the primary food sources for blue crabs in the Neuse (E. T. Sullivan and D. Gaskill, unpublished manuscript), hypoxia-induced food limitation may drive crab population dynamics.

Understanding what regulates populations has been a central issue in ecology for decades (Krebs 1995); more recently ecologists are expanding this question to address how human modifications to ecosystem processes may impact the regulation of populations. Even though the problem of hypoxia in nearshore and estuarine waters is common worldwide (Diaz and Rosenberg 1995), and it is known that patch characteristics can alter species interactions and subsequent population dynamics (Fagan et al. 1999), it is not known whether crab population dynamics differ under ecosystem regimes dominated by static vs. transient patches. Different hypotheses have been suggested as to the role of hypoxia in altering blue crab populations. One hypothesis is that cannibalism caused by hypoxiainduced habitat restriction further increases the high rates of juvenile cannibalism (Hines and Ruiz 1995). Other hypotheses are that hypoxia-induced faunal depletion results in food limitation (E. T. Sullivan and D. Gaskill, unpublished manuscript) or that decreases in available habitat increase antagonistic encounters among adult crabs to the point that cannibalism is unchanged or decreases due to the high degree of interference (Eggleston 1998). In estuaries, the maximum hypoxic extents and durations vary both seasonally and annually (Selberg et al. 2001) making it difficult to determine from empirical data alone which hypothesis is most strongly supported.

In this paper, we develop a detailed, synthetic model that links ecosystem and population dynamics to explore how the extent and duration of hypoxic patches alter crab population dynamics. We focus our investigation on the specific mechanisms hypothesized to drive the changes in crab population dynamics, namely hypoxia-induced changes in the rate of cannibalism or degree of food limitation. Our framework (Fig. 1) is based on hierarchical levels (e.g., O'Neill et al. 1986, Salthe 1993) defined by emergent properties (Bergandi and Blandin 1998, Bergandi 2000). Despite the potentially broad relevance of hierarchy theory within ecology, relatively few studies in population or community ecology have adopted this framework.

In our model, we explore how transient hypoxic patches acting on individual crabs alter population-level relationships within the estuarine system. We give particular attention to the causes of crab mortality, variation in recruitment, and resulting crab population structure. An increased understanding of how transient habitat dynamics alter crab population dynamics sets the stage for future modeling exploration of the impacts of fisheries and the potential for collapse due to overharvest (Roughgarden and Smith 1996, Eggleston 1998, Miller 2003).

Because key components of crab dynamics are both size and context dependent (e.g., Jachowski 1974, Pihl et al. 1991, Das and Stickle 1993) we need a detailed representation of individuals to accurately characterize crab interactions with their habitats, prey, and each other. We are able to develop a detailed individual-based model (IBM) to investigate the interplay between hypoxia and crab population dynamics because blue crabs constitute one of the most widely studied marine organisms (Epifanio 1995) with an extensive literature providing detailed information on crab behavior, development, ecology and physiology. The long history of basic and applied research in this model system allows us to incorporate a degree of detail and realism at the individual level not possible for most ecological systems.

One advantage of using IBMs is that population-level dynamics can be observed using knowledge about the 


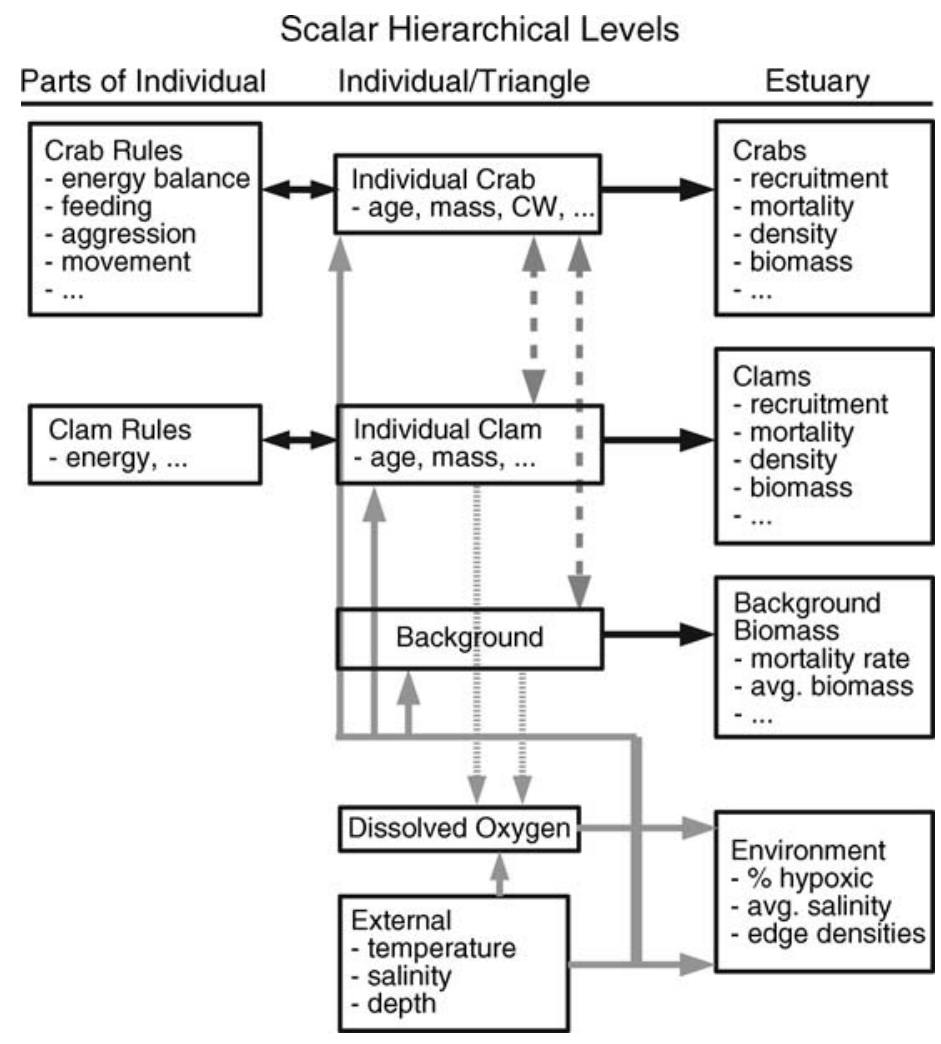

behaviors and properties of individuals enabling the model to be used as a surrogate experimental system to develop and assess ecological theory (Olson and Sequeira 1995, Grimm 1999) when issues of spatiotemporal scale and other factors prohibit doing so through direct manipulations in the real system. Our comprehensive model assessment enabled us to address two questions in the main body of this paper: (1) Do transient patches impact blue crab populations in the same manner as static patches? (2) Are these changes caused primarily by increased cannibalism or food limitation? Finally, we discuss how decomposing the complex system hierarchically using emergent properties contributes to the unification of ecosystem and population perspectives in estuarine ecology.

\section{Conceptual Overview of the Model Estuary}

To make the model more realistic, we focused on the Neuse River estuary in North Carolina (Fig. 2; Appendix A: Fig. A2). The portion of this estuary modeled is $35 \mathrm{~km}$ long with a maximum width of $\sim 8$ $\mathrm{km}$, an average depth of $3.5 \mathrm{~m}$, and a maximum depth of $\sim 7 \mathrm{~m}$. This estuary supports a major crab fishery and has been the focus of empirical studies quantifying the spatial extent of hypoxia in the estuary (Selberg et al. 2001, Buzzelli et al. 2002) in conjunction with water quality, temperature, salinity, and other environmental variables (Luettich et al. 1999).
The hierarchical nature of the model is illustrated in Fig. 1. The four main interdependent components are (1) the environment variables of dissolved oxygen concentration (DO), salinity, temperature, and depth; (2) a model of clams, which are a crab's primary food source; (3) a model of background prey representing an aggregate crab food source; and (4) an individual-based model (IBM) of blue crabs. The overall estuary is viewed as a complex system and decomposed hierarchically (Fig. 1) into three scalar levels using the principle that each level should have at least one emergent property (Bergandi and Blandin 1998). Those interested in the full implementation details are referred to Appendix A.

\section{Environment variables}

The two-dimensional estuary is discretized into nested triangles with depth, temperature, and salinity represented on the nodes of the finest level triangles with values within the triangle found by interpolation. Dissolved oxygen (DO), clams, and background prey are considered homogeneous across each fine-level triangle. The nested triangulation also facilitates crab movement and enables neighboring crabs to be found efficiently. Updating of the estuary environment variables, clams, and background prey is done every 24 hours, while crab updating is done on average once per hour or more frequently if crabs interact.

Modeled temperature, salinity, and DO vary spatially and temporally due to systematic and random effects 

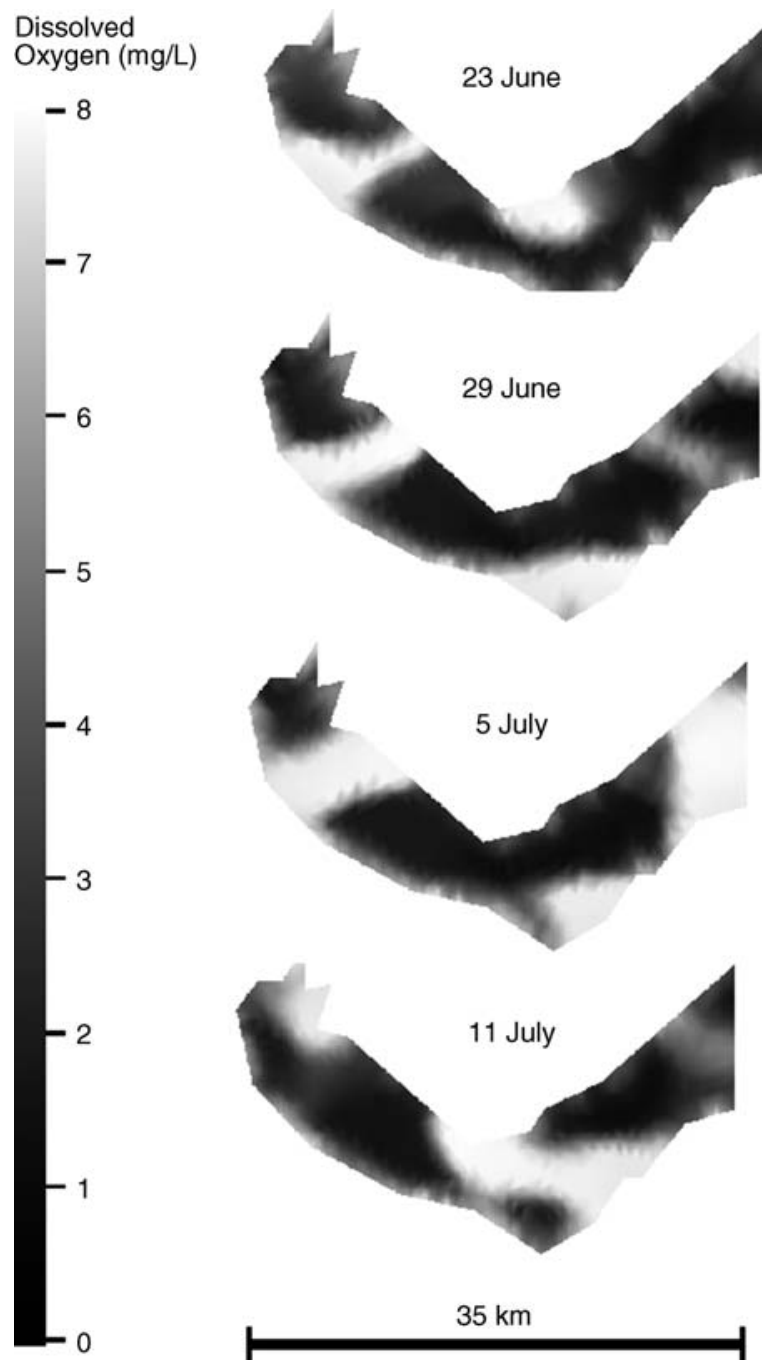

$35 \mathrm{~km}$

FIG. 2. Snapshots of the modeled dissolved oxygen (DO) in the portion of the Neuse River estuary, North Carolina, USA, during year 39 . The portion of the estuary modeled is $\sim 35 \mathrm{~km}$ long with a maximum width of $\sim 8 \mathrm{~km}$. Darkest areas indicate hypoxic areas (DO $<2 \mathrm{mg} / \mathrm{L}$ ). The snapshots show how the simulated hypoxic areas change across the estuary over the 2.5 week period.

(see Appendix A: section A.3). The goal here is to produce environmental variables that behave plausibly and similarly to what is known about the actual estuary. Temperature and salinity influence biological processes, but are not influenced by them. Seasonal fluctuations in expected temperature are driven by a combination of sinusoidal functions so that deeper areas are slightly warmer in winter than summer (and slightly cooler in summer than winter) while the opposite pattern holds for shallow waters over winter and summer. Autocorrelated temporal and spatial variation (generated as a Gaussian random field) is added to these systematic effects (Appendix A: sections A.3.1-A.3.2). Similarly, salinity is modeled to incorporate systematic effects so that salinity increases toward the mouth of the estuary, shallower parts of the estuary are less saline, and realistic seasonal fluctuations occur. Autocorrelated temporal and spatial variation is also incorporated.

DO both influences and is influenced by biological processes (clams and background prey). In the model, DO changes on a daily basis on each fine-level triangle in response to gains from re-aeration from the surface and random mixing events, and losses due to sediment and biological oxygen demand. These processes are influenced by the current DO and temperature, and biological oxygen demand increases as the benthic biomass (clams plus background prey) increases. The maximum amount of the total estuary hypoxic during the summer ranges from $40 \%$ to $60 \%$ (Selberg et al. 2001, Buzzelli et al. 2002). Hypoxic patches are highly transient with most locations experiencing a number of hypoxic periods during the summer (Fig. 2). The median time that the deepest areas remain continuously hypoxic is $\sim 9 \mathrm{~d}$ (see Appendix B: section B.2.2).

\section{Model of clams and background prey}

To simplify model complexity, we only model a single bivalve (Macoma balthica, which we refer to as simply "clams"). Background prey represents an aggregate of different possible crab prey such as other benthic species and dead organisms. Clam and background prey models are represented at the scale of each finest level triangle. Clams in the Neuse are assumed to live for a maximum of eight years and engage in two discrete spawning events each year (and of March and August; Gilbert 1978, Harvey and Vincent 1989). Each fine-level triangle thus stores 16 aggregate age classes for clams along with the number, size, and mass of the clams in each age class. Clams have to reach a shell length of $1 \mathrm{~cm}$ to spawn and the number of eggs produced depends on the size of the clam (Commito 1982, Honkoop et al. 1998). Recruitment is positively related to estuary-wide egg production, but is inhibited on individual triangles by both local density (no. $/ \mathrm{m}^{2}$ ) and biomass of clams $\left(\mathrm{g} / \mathrm{m}^{2}\right)$. Within each age class, clams grow according to a model that closely follows the bivalve model proposed by Solidoro et al. (2000). Clam growth rates are influenced by temperature and DO of the triangle. Clams suffer mortality due to crab predation via a detailed crab foraging model which determines the number of clams of each age class that die due to crab attacks on each triangle. Clams that are not eaten have probabilities of death due to other unspecified causes, hypoxia, and temperature.

The background prey on each triangle represents an aggregate of a wide class of organisms and is modeled using a modified logistic growth model. As with clams, background prey is decreased by hypoxia and crab predation. Adult crabs will feed on this alternative food source if insufficient clams are found to satiate them. Because crabs are restricted in the size of prey they can 
feed on, background prey plays an important role in the survival of early instar crabs.

\section{Crab model}

In a typical blue crab's life cycle, females reach sexual maturity at $1-1.5 \mathrm{yr}$ at instars $18-19$, at which point they mate and start producing eggs (van den Avyle 1984). Following spawning, the female carries the eggs for approximately two weeks until the larvae hatch and are transported to the ocean in which they progress through seven to eight zoea stages. Upon reaching the megalops stage, they are recruited back into the estuary and reach the first instar or first crab stage and continue to grow via molting (shedding of their exoskeleton) until reaching sexual maturity. Most crabs live less than three years.

The model is based on a slightly simplified version of this life cycle (Appendix A: section A.5). While individual crabs reach sexual maturity at the same time as real crabs, the eggs produced by all female crabs in the model estuary on a single day are placed in a common "egg pot" and their temperature dependent development is tracked. The mortality rate within the "egg pot" is assumed to be constant, but slower development results in a smaller proportion surviving to instar 7-the instar at which crabs are instantiated as individuals into the model estuary. Reaching the seventh instar takes approximately 80-145 days from spawned egg. The actual number of crabs instantiated each day is a proportion of all crabs reaching the equivalent of the seventh instar on a given day. This proportion varies randomly, but decreases on average as the density of $7+$ instar crabs increases in the estuary. All other crabs at the equivalent of the seventh instar on that day never recruit. The above simplification in the life cycle avoids the computational burden of modeling very large numbers of individual larvae and early instar crabs yet still captures the stochastic and density dependent nature (Tang 1985, Epifanio 1995) of crab recruitment.

After individual crabs have been recruited into the estuary, the behavior of these individuals is controlled by sub-models that alter the crab's state variables. Each of these sub-models, along with the associated empirical information upon which they are based, is discussed in section A.5 of Appendix A. Individual crabs are randomly updated on average once per hour, but this is more frequent when crabs interact. Every time a crab is updated, all of its state variables are updated by applying its sub-models within the crab's current environment and habitat conditions. A description of the key crab sub-models and the order in which they are executed follows.

When a crab is updated, it is first determined whether the crab died as a result of aggression from another crab or from other causes that include exposure to temperature extremes, starvation, a lack of oxygen, or reaching its life expectancy. If the crab is dead, it is flagged as such and removed from the model. If the crab is still alive, it is then determined whether the crab has gained enough mass to exceed the upper bound placed on its mass by it its current carapace width (CW). If so, the crab starts molting and its state variables are altered to prevent the crab from moving, and its metabolic rate increases during the molting process. The overall duration of molting is indirectly controlled via the effect of temperature on the crab's maximum metabolic rate.

The next step of the updating process involves computing the crab's energy balance and involves determining how much energy (i.e., mass) it has gained and lost since it was last updated. Mass gains can only occur by a crab finding prey (clams, or background prey) and the amount of prey found and ingested depends on the duration of time since its last update along with the density and size structure of the prey at its current location. Crabs only feed when their stomachs become empty $(<10 \%$ full), while the rate at which their stomachs empty is indirectly dependent on temperature. Background prey has the lowest caloric content, clams are intermediate, and conspecifics (which crabs can also feed on) are the highest. Energy losses are determined by egestion, metabolic costs, and movement costs - all of which are temperature dependent. That is, as a crab's metabolism slows down as temperature decreases, so does its rate of movement. An overall energy surplus (or deficit) for a crab is translated into mass gain (or loss) for crabs that can still molt. For sexually mature females, a surplus is translated into reproductive output. If a mature female has lost a lot of mass, then this loss must be made up before energy is devoted to reproductive output. Once a female crab has produced the number of eggs to be released, it spawns and the eggs she carries are added to the "egg pot" for that day.

A crab's movement sub-model is key to enabling crab-crab interactions and thus hypoxia-induced mortality. Unlike most IBMs in ecology, in which individuals move between discrete cells on updates, crab movement is modeled continuously in time and space. When a crab is updated above, its rate and direction of movement are altered based on its local environment (water depth, salinity, oxygen content) and whether it interacted with another crab. Between updates, its rate and direction of movement are constant. The rate depends on temperature and whether it is fleeing another crab or sub-optimal environmental conditions. The direction of movement is based on its current environmental conditions (e.g., toward non-hypoxic areas, shallower areas if small, deeper areas if adult, more saline areas if adult female, less saline areas if an adult male) or if it is fleeing an attacking crab. After the future rate and direction of movement have been determined, the set of neighboring crabs is found. If this set is nonempty, one of those crabs is randomly selected (based on distance) to potentially interact with the current crab at some point in the future. The outcome of crab-crab interactions depends on the size differential between the two interacting crabs, their sex, molt status, and gut fullness. In general, bigger crabs kill smaller crabs (but if 
they are too small the bigger crab will not bother with them), females on their terminal molt will mate with larger males, but are cannibalized by larger non-molting females.

\section{Methods}

Model assessment

Model assessment is essential for gauging the adequacy and utility of any model (Rykiel 1996, Ford 2000). We used three sets of assessment criteria across the hierarchical levels in Fig. 1. The first set of criteria are based on the principles that lower-level model propositions should be based on empirical findings, that concept definitions should be consistent, that ad hoc model propositions which include or exclude special circumstances should be avoided and that model propositions should be as simple as possible. Describing each sub-model (Appendix A) serves not only as a description of the mathematical functions used, but also whether these criteria are fulfilled. In addition, a process to verify the model implementation (i.e., that the model has been built correctly relative to this model design document [Balci 1994, Zeigler et al. 2000]) is applied (Appendix B: section B.1).

The next set of criteria focus at a higher hierarchical level to gauge whether the behaviors of the sub-models under variable conditions are reasonable. For example, given the functional specifications of clam growth, mortality and recruitment (see Appendix A: section A.4) does a stable clam population develop? How fast do clams reach maturity under the specified environmental regime? What is the distribution of clam biomass over the estuary? Given the hierarchical dependencies between the sub-models, the habitat variables are assessed first, followed by the clam and background food sub-models, and finally the crab sub-model. As the present paper is primarily about how the extent and duration of hypoxic patches alter crab population dynamics, we direct interested readers to Appendix B for all the assessment details.

Finally, the three scenarios described below address our main objectives, specifically whether crab population dynamics differ under fixed vs. dynamic patches and whether these differences are the result of food limitation or increased cannibalism.

\section{Overview of three scenarios}

The first class of scenarios examines the influence of maximum hypoxic extent and duration on prey abundance and crab population dynamics. Maximum hypoxic extent is defined as the maximum percentage of the estuary which is hypoxic over a season. Four maximum extent levels are considered: $15 \%, 30 \%, 45 \%$, and $60 \%$ which are crossed with three hypoxic durations (short, long, and fixed) for how long a given location in the estuary remains hypoxic. The different extents are generated by altering the rate of oxygen usage by the sediments (see Appendix A: section A.3.4). Short and long hypoxic durations are generated by altering the time correlation of the hypoxic patches (Appendix A: section A.3.1) while a fixed duration or static patch is generated by assuming no spatial randomness in temperature or in mixing (i.e., $X=1$ in Eq. A.3 of Appendix A and $Z=1$ in Eq. A.9 of Appendix A). The other model parameter values (Appendix C: Table C1) remain the same.

The second class of scenarios is aimed at determining how the crab population responds to different levels of clam and background food availability. Three levels are considered: limited, default, and unlimited. The foodlimited case is generated by decreasing the upper bound on clam biomass recruitment (Appendix A: section A.4.3) by one-half from its default value of $850 \mathrm{~g} / \mathrm{m}^{2}$ and decreasing the background prey carrying capacity by one-half from its default value of $400 \mathrm{~g} / \mathrm{m}^{2}$ (Appendix A: section A.4.4). The food-unlimited case corresponds to turning off all clam and background prey mortality due to hypoxia while using the default values for clam biomass recruitment and background carrying capacity. These three food levels are crossed with the four levels of hypoxic extent and a short hypoxic duration is used in all simulations. Thus, the default case in this scenario is exactly the same as short hypoxic duration in the first class of scenarios and attempts to represent typical estuary dynamics.

The third class of scenarios involves altering the maximum interaction distance or "cannibalism potential" between crabs. Because the first two scenarios show cannibalism to be a very important factor in structuring crab populations, it is important to determine how the population changes under different assumptions about cannibalism potential. Three cases are considered: small, default, and large which correspond to multiplying the maximum interaction distance between crabs (Appendix A: section A.5.3) by factors of $0.25,1$, and 2, respectively. Each interaction distance is crossed with the four maximum hypoxic extents $(15 \%, 30 \%, 45 \%$, and $60 \%$ ) under a short hypoxic duration. Again, default corresponds to our "best guess" of current conditions.

For all simulations run under all three scenarios, the model is started with the estuary completely devoid of clams and crabs. Clam spat are input into the estuary at the spring and fall recruitments at a maximum density of 200 individuals $/ \mathrm{m}^{2}$ for two years. Clams are allowed to grow and develop free of predation by crabs for 20 years. At the end of this time, crab eggs are introduced into the maturation pot for two years in addition to any eggs generated by the maturing crabs in the estuary. Crab interactions do not occur during the first year crabs are introduced and the model is run for 10 years, to the beginning of year 30 , to burn it in.

To facilitate comparison among the different scenarios run, the mean and standard deviation (SD) of the daily estuary-wide exports are computed between years 30 to 39 for the days between 1 June and 30 September 
( $n=1220)$, since this is when most model dynamics occur.

\section{RESULTS}

Introduction to model behavior and scenario comparison

MPEG movies for all scenarios are given in Appendix E. The movies in Introduction to Model Dynamics provide a general overview of model dynamics over year 39 for $45 \%$ maximum hypoxic extent and short hypoxic duration - a case which we think most closely resembles the dynamics in the estuary (Selberg et al. 2001). The values shown in all movies are in good agreement with the values obtained from the literature (see Appendix B: section B.3). The "Environment" movie shows temperature (C), salinity (psu), depth (m), and DO $(\mathrm{mg} / \mathrm{L})$. From this movie, it can be seen that deeper areas were warmer in winter than shallower areas and the reverse was true in summer. Salinity increased toward the mouth of the estuary and fluctuated seasonally. A number of large hypoxic patches formed in late spring and move around the estuary before dissipating in fall. Depth remained constant. The "Clams \& Background" movie showed the associated distribution of clam biomass, clam density, background prey biomass, and DO. Both clam biomass and background prey were patchy, decreased toward the mouth of the estuary, decreased toward deeper areas, and changed little over the year. Clam density drops dramatically in deeper areas closer toward the mouth of the estuary which experienced greater hypoxia, but the clam population was always replenished by the two recruitment events. Finally, the movie "Crabs Density and Biomass" shows the associated crab density for the aggregated instar classes 7-12 and 13-17 along with total crab biomass. The highest densities for 7-12 and 13-17 instar crabs occurred along the shallower edges of the estuary where hypoxia was least likely to occur. These densities decreased as the crabs molt into higher instar classes. Since $18+$ instar crabs dominate total crab biomass and since these crabs prefer deeper waters, the results of hypoxic avoidance can be easily seen.

The other movies in Appendix E show DO, clams, and background prey both without (year 19) and with (year 39) crabs present in the estuary for the three scenarios considered. For the first scenario, it is clear that hypoxic patches of short and long duration were made up of more than a single patch and the location of these patches changed dynamically with time. Under fixed duration, the single large patch was static, but formed in the spring, reached its maximum extent in summer and dissipated in fall.

The plots (Fig. 3) of clam and crab biomass under short hypoxic duration and a $45 \%$ maximum hypoxic extent show the initial 20 year burn-in when crabs were not present in the estuary (years 0-20), the crab burn-in (years 20-30), and finally years 30-39, over which the population-level variables were summarized. With the introduction of crabs, clam biomass decreased by $\sim 200$

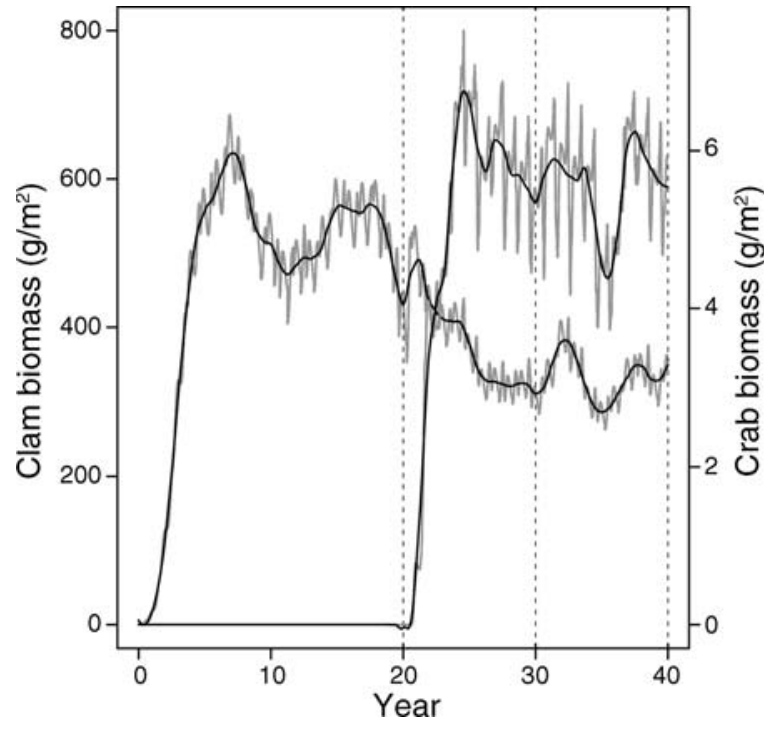

FIG. 3. Time series of the average clam biomass and the average crab biomass in the estuary. The first 20 years correspond to no crabs in the estuary, years 20-30 correspond to the burn-in for the crabs, and years 30-40 are the period over which the different hypoxic patches are compared. Solid lines were generated using a Loess smoother.

$\mathrm{g} / \mathrm{m}^{2}$ or $33 \%$, while average crab biomass was. Variables of direct relevance to the questions addressed by the three scenarios are summarized in Tables 1-3. Additional estuary level variables are summarized in Appendix C: Tables C2-C4 (Appendix C also contains supplementary plots).

\section{Scenario class I: altering hypoxic extent and duration}

To understand the impacts of transient hypoxic patches on estuarine ecosystems, we need to understand how variation in characteristics of patches affect the component populations. This scenario explored how changes to the extent or duration of hypoxic patches affect clams, background prey, and crabs.

How do hypoxic extent and duration affect clams, background prey, and crabs?-Both increasing hypoxic duration (short to fixed) and maximum hypoxic extent (15\% to $60 \%$ ) increased the number of days deeper areas remained continuously hypoxic (Fig. 4). For example, in year 39 under short duration, the median number of days areas deeper than $4 \mathrm{~m}$ remained continuously hypoxic increased from $\sim 3 \mathrm{~d}$ at $15 \%$ hypoxic extent to $\sim 9 \mathrm{~d}$ at $60 \%$ hypoxic extent. Under long duration, the median increased from $\sim 2 \mathrm{~d}$ to $15 \mathrm{~d}$ across the same extents. Under fixed duration and hypoxic extents greater than $15 \%$, depths $>4 \mathrm{~m}$ were continuously hypoxic from June to September.

These hypoxic durations were long enough to alter the average background and clam biomass in the estuary. Over the estuary, both background and clam biomass decreased (due to hypoxia induced mortality) with 
TABLE 1. Estuary-wide summaries of hypoxic extent crossed with duration under scenario class I.

\begin{tabular}{|c|c|c|c|c|c|c|}
\hline \multirow[b]{3}{*}{ Parameters } & \multicolumn{6}{|c|}{ Hypoxia duration } \\
\hline & \multicolumn{3}{|c|}{$15 \%$ maximum hypoxia } & \multicolumn{3}{|c|}{$30 \%$ maximum hypoxia } \\
\hline & Short & Long & Fixed & Short & Long & Fixed \\
\hline $\begin{array}{l}\text { Background }\left(\mathrm{g} / \mathrm{m}^{2}\right) \\
\text { Clam biomass }\left(\mathrm{g} / \mathrm{m}^{2}\right)\end{array}$ & $\begin{array}{l}131(7) \\
460(23)\end{array}$ & $\begin{array}{l}115(7) \\
407(27)\end{array}$ & $\begin{array}{l}147(7) \\
301(18)\end{array}$ & $\begin{array}{l}140(8) \\
419(26)\end{array}$ & $\begin{array}{l}113(6) \\
356(29)\end{array}$ & $\begin{array}{l}125(9) \\
226(19)\end{array}$ \\
\hline \multicolumn{7}{|c|}{ Crab density $\left(\left[\right.\right.$ no. $\left.\left.\times 10^{-2}\right] / \mathrm{m}^{2}\right)$} \\
\hline $\begin{array}{l}\text { Instar } 7-12 \\
\text { Instar } 13-17 \\
\text { Instar } 18+\end{array}$ & $\begin{array}{c}15.66(17.94) \\
2.84(1.42) \\
2.30(0.2)\end{array}$ & $\begin{array}{c}13.63(15.79) \\
2.43(1.17) \\
2.17(0.23)\end{array}$ & $\begin{array}{l}9.83(11.69) \\
2.17(1.38) \\
1.35(0.08)\end{array}$ & $\begin{array}{c}14.84(17.63) \\
2.89(1.65) \\
1.94(0.23)\end{array}$ & $\begin{array}{c}11.96(13.86) \\
2.17(1.19) \\
1.81(0.21)\end{array}$ & $\begin{array}{l}7.86(9.62) \\
1.72(1.33) \\
0.94(0.06)\end{array}$ \\
\hline \multicolumn{7}{|c|}{ Total mortality rate $\left(\left[\right.\right.$ no. $\left.\left.\times 10^{-4}\right] / \mathrm{h}\right)$} \\
\hline $\begin{array}{l}\text { Instar } 7-12 \\
\text { Instar } 13-17 \\
\text { Instar } 18+\end{array}$ & $\begin{array}{l}8.16(5.11) \\
7.31(3.16) \\
2.46(1.83)\end{array}$ & $\begin{array}{l}7.97(5.02) \\
7.12(3.38) \\
2.16(1.68)\end{array}$ & $\begin{array}{l}7.19(5.33) \\
8.05(3.54) \\
3.10(2.26)\end{array}$ & $\begin{array}{l}8.37(5.31) \\
8.24(3.78) \\
2.64(2.05)\end{array}$ & $\begin{array}{l}7.53(4.96) \\
7.65(3.96) \\
2.44(1.99)\end{array}$ & $\begin{array}{l}6.71(5.42) \\
8.90(4.85) \\
3.38(2.75)\end{array}$ \\
\hline
\end{tabular}

Notes: For all variables, the mean and SD were calculated for the daily model exports for years 30-39 between 1 June and 30 September $(n=1220)$.

increasing hypoxic extent and duration, (background 147 to $66 \mathrm{~g} / \mathrm{m}^{2}$ and clams 460 to $147 \mathrm{~g} / \mathrm{m}^{2}$, Table 1).

Average crab density decreased with increasing extent and duration, and the relative importance of hypoxic duration varied with hypoxic extent. The highest crab densities for 7-12, 13-17, and 18+ instar crabs were observed for low hypoxic extents and short durations while the lowest crab densities generally occurred under fixed duration and large hypoxic extents (Table 1). Increasing hypoxic extent from $15 \%$ to $60 \%$ decreased the density of 7-12 instar crabs across short, long, and fixed duration to $26 \%, 20 \%$, and $43 \%$, respectively, of the $15 \%$ hypoxic extent values; while the density of $13-$ 17 instar crabs decreased by $\sim 50 \%$, and the density of $18+$ instar crabs decreased to $33 \%, 35 \%$, and $41 \%$ of the lower hypoxic extent values, respectively. Within each maximum hypoxic extent, the result of increasing hypoxic duration on density was generally smaller than increasing hypoxic extent and varied within each hypoxic extent considered.
Similar to crab density, average crab biomass was highest at the shortest hypoxic duration and smallest maximum hypoxic extent $\left(7.84 \mathrm{~g} / \mathrm{m}^{2}\right)$ and lowest at fixed duration and $60 \%$ hypoxic extent $\left(2.01 \mathrm{~g} / \mathrm{m}^{2}\right)$. Within short, long, and fixed durations, increasing hypoxic extent from $15 \%$ to $60 \%$ decreased crab biomass to $36 \%$, $37 \%$, and $43 \%$, respectively, of the $15 \%$ hypoxic extent values. The influence of duration within hypoxic extent was similar to that observed for crab density: smaller than that of hypoxic extent.

What is the explanation for the differences in crab abundance?-Given the differences observed in crab abundance under the different hypoxic patch types, we now explore what factors were responsible. In summary, under both transient and static hypoxic patches, the differences in crab population dynamics were not the result of food limitation, but altered cannibalism rates and altered rates of crab egg production resulting from changes in spatial distribution.

TABLE 2. Effect of altering the levels of clam and background prey.

\begin{tabular}{|c|c|c|c|c|c|c|}
\hline \multirow[b]{3}{*}{ Parameters } & \multicolumn{6}{|c|}{ Food availability } \\
\hline & \multicolumn{3}{|c|}{$15 \%$ maximum hypoxia } & \multicolumn{3}{|c|}{$30 \%$ maximum hypoxia } \\
\hline & Limited & Default & Unlimited & Limited & Default & Unlimited \\
\hline $\begin{array}{l}\text { Background }\left(\mathrm{g} / \mathrm{m}^{2}\right) \\
\text { Clam biomass }\left(\mathrm{g} / \mathrm{m}^{2}\right)\end{array}$ & $\begin{array}{c}43(2) \\
203(11)\end{array}$ & $\begin{array}{l}131(7) \\
460(23)\end{array}$ & $\begin{array}{l}145(11) \\
529(27)\end{array}$ & $\begin{array}{c}46(3) \\
176(15)\end{array}$ & $\begin{array}{l}140(8) \\
419(26)\end{array}$ & $\begin{array}{l}170(12) \\
549(29)\end{array}$ \\
\hline \multicolumn{7}{|c|}{ Crab density $\left(\left[\right.\right.$ no. $\left.\left.\times 10^{-2}\right] / \mathrm{m}^{2}\right)$} \\
\hline $\begin{array}{l}\text { Instar } 7-12 \\
\text { Instar } 13-17 \\
\text { Instar } 18+\end{array}$ & $\begin{array}{c}10.07(11.25) \\
1.25(0.42) \\
1.36(0.1)\end{array}$ & $\begin{array}{c}15.66(17.94) \\
2.84(1.42) \\
2.30(0.2)\end{array}$ & $\begin{array}{c}16.33(19.46) \\
3.05(1.58) \\
2.32(0.23)\end{array}$ & $\begin{array}{l}9.00(9.87) \\
1.32(0.53) \\
1.06(0.13)\end{array}$ & $\begin{array}{c}14.84(17.63) \\
2.89(1.65) \\
1.94(0.23)\end{array}$ & $\begin{array}{c}14.43(17.36) \\
2.97(1.76) \\
1.96(0.22)\end{array}$ \\
\hline \multicolumn{7}{|c|}{ Total mortality rate $\left(\left[\right.\right.$ no. $\left.\left.\times 10^{-4}\right] / \mathrm{h}\right)$} \\
\hline $\begin{array}{l}\text { Instar } 7-12 \\
\text { Instar } 13-17 \\
\text { Instar } 18+\end{array}$ & $\begin{array}{l}7.33(4.84) \\
4.83(3.03) \\
1.93(1.83)\end{array}$ & $\begin{array}{l}8.16(5.11) \\
7.31(3.16) \\
2.46(1.83)\end{array}$ & $\begin{array}{l}8.42(5.26) \\
7.39(3.22) \\
2.48(1.77)\end{array}$ & $\begin{array}{l}7.00(4.63) \\
5.89(3.62) \\
2.47(2.38)\end{array}$ & $\begin{array}{l}8.37(5.31) \\
8.24(3.78) \\
2.64(2.05)\end{array}$ & $\begin{array}{l}8.41(5.73) \\
8.43(3.79) \\
2.65(2.1)\end{array}$ \\
\hline
\end{tabular}

Notes: The food-limited case corresponds to decreasing the upper bound on clam biomass recruitment by one-half from its default value of $850 \mathrm{~g} / \mathrm{m}^{2}$ and decreasing the background prey carrying capacity by one-half from its default value of $400 \mathrm{~g} / \mathrm{m}^{2}$. The food-unlimited case corresponds to turning off all clam and background mortality due to hypoxia. A short hypoxic duration was used in all scenarios. 
TABLE 1. Extended.

\begin{tabular}{|c|c|c|c|c|c|}
\hline \multicolumn{6}{|c|}{ Hypoxia duration } \\
\hline \multicolumn{3}{|c|}{$45 \%$ maximum hypoxia } & \multicolumn{3}{|c|}{$60 \%$ maximum hypoxia } \\
\hline Short & Long & Fixed & Short & Long & Fixed \\
\hline $146(7)$ & $106(6)$ & $98(9)$ & $94(10)$ & $66(5)$ & $80(8)$ \\
\hline $334(29)$ & $268(25)$ & $191(21)$ & $190(25)$ & $156(19)$ & $149(18)$ \\
\hline $11.06(13.46)$ & $8.08(9.56)$ & $7.02(8.52)$ & $4.08(5.07)$ & $2.79(3.71)$ & $4.22(5.25)$ \\
\hline $2.56(1.61)$ & $1.83(1.15)$ & $1.41(1.13)$ & $1.54(0.96)$ & $1.23(0.78)$ & $1.18(0.91)$ \\
\hline $1.45(0.21)$ & $1.37(0.2)$ & $0.77(0.06)$ & $0.76(0.14)$ & $0.75(0.14)$ & $0.55(0.05)$ \\
\hline $8.57(6.13)$ & $7.63(4.95)$ & $7.19(5.36)$ & $10.66(15.37)$ & $10.45(16.21)$ & $8.03(8.2)$ \\
\hline $8.89(4.47)$ & $8.21(4.94)$ & $9.67(5.51)$ & $8.32(5.12)$ & $7.50(5.59)$ & $9.14(5.77)$ \\
\hline $2.96(2.62)$ & $2.58(2.4)$ & $3.22(3)$ & $3.29(3.32)$ & $2.86(3.25)$ & $3.52(3.72)$ \\
\hline
\end{tabular}

At least three model behaviors can be given to support the conclusion that food limitation was not important. First, average gut fullness and average food quality (Appendix C: section C.2) for the three instar classes considered show no dramatic changes with different hypoxic durations or extents. Second, food limitation should increase the time required for crabs to reach the 18 th instar, but no such increases were observed (Appendix C: Fig. C5). Third, the highest individual crab survival occurred at the greatest hypoxic extents under a fixed hypoxic duration (Appendix C: Fig. C4), yet these simulations also had the lowest clam and background biomass. Finally, the rate of total mortality from all causes (aggression, starvation, senescence, and asphyxiation due to lack of oxygen) divided by the density of crabs in the instar class, was only slightly larger than mortality due just to aggression for 13-17 and $18+$ instar classes (Table 1), indicating that aggression was the primary cause of mortality for larger crabs. Two percent of all crabs in the estuary were randomly flagged when initialized to monitor major events in the lives of these individuals; in particular, at what development stage they experience mortality. Tracking the causes of mortality indicates that over all hypoxic extents, only $6 \%$ to $19 \%$ of $7-12$ instar crab mortality was due to starvation. For $13-17$ and 18+ instar classes, the percentage of crabs dying due to either asphyxiation or starvation was less than $2 \%$ across all hypoxic extents. All of these facts provide strong evidence that the decreases in clam and background prey were not primarily responsible for the decreases in crab density.

Decreased crab abundance under increasing hypoxic extent resulted primarily from two factors. First, increasing hypoxic extent increased the density-dependent rate of mortality for a given crab density and second, lower estuary level rates of egg production resulted in lower rates of juvenile recruitment. For the first factor, as crab abundance declined with increasing hypoxia, crab-crab encounter rates and subsequent rates of

TABLE 2. Extended.

\begin{tabular}{|c|c|c|c|c|c|}
\hline \multicolumn{6}{|c|}{ Food availability } \\
\hline \multicolumn{3}{|c|}{$45 \%$ maximum hypoxia } & \multicolumn{3}{|c|}{$60 \%$ maximum hypoxia } \\
\hline Limited & Default & Unlimited & Limited & Default & Unlimited \\
\hline $\begin{array}{c}38(3) \\
133(18)\end{array}$ & $\begin{array}{l}146(7) \\
334(29)\end{array}$ & $\begin{array}{l}195(14) \\
565(31)\end{array}$ & $\begin{array}{l}29(3) \\
84(11)\end{array}$ & $\begin{array}{r}94(10) \\
190(25)\end{array}$ & $\begin{array}{l}219(16) \\
578(35)\end{array}$ \\
\hline $\begin{array}{l}5.39(6.02) \\
1.07(0.52) \\
0.79(0.11)\end{array}$ & $\begin{array}{c}11.06(13.46) \\
2.56(1.61) \\
1.45(0.21)\end{array}$ & $\begin{array}{c}11.84(14.33) \\
2.60(1.62) \\
1.52(0.21)\end{array}$ & $\begin{array}{l}2.24(2.6) \\
0.84(0.44) \\
0.50(0.08)\end{array}$ & $\begin{array}{l}4.08(5.07) \\
1.54(0.96) \\
0.76(0.14)\end{array}$ & $\begin{array}{l}6.95(8.6) \\
1.97(1.23) \\
1.00(0.16)\end{array}$ \\
\hline $\begin{array}{l}7.67(5.51) \\
6.70(4.43) \\
2.56(2.78)\end{array}$ & $\begin{array}{l}8.57(6.13) \\
8.89(4.47) \\
2.96(2.62)\end{array}$ & $\begin{array}{l}9.82(14.23) \\
9.12(4.57) \\
2.79(2.42)\end{array}$ & $\begin{array}{l}9.90(15.09) \\
6.41(4.89) \\
3.04(3.9)\end{array}$ & $\begin{array}{c}10.66(15.37) \\
8.32(5.12) \\
3.29(3.32)\end{array}$ & $\begin{array}{l}14.5(20.86) \\
9.10(5.21) \\
3.05(2.92)\end{array}$ \\
\hline
\end{tabular}


TABLE 3. Estuary-wide summaries for altering cannibalism potential via crab-crab maximum interaction distance (see Appendix A: section A.5.3).

\begin{tabular}{|c|c|c|c|c|c|c|}
\hline \multirow[b]{3}{*}{ Parameters } & \multicolumn{6}{|c|}{ Interaction distance } \\
\hline & \multicolumn{3}{|c|}{$15 \%$ maximum hypoxia } & \multicolumn{3}{|c|}{$30 \%$ maximum hypoxia } \\
\hline & Small & Default & Large & Small & Default & Large \\
\hline Background $\left(\mathrm{g} / \mathrm{m}^{2}\right)$ & $57(5)$ & $131(7)$ & $208(12)$ & $50(5)$ & $140(8)$ & $210(11)$ \\
\hline Clam biomass $\left(\mathrm{g} / \mathrm{m}^{2}\right)$ & $361(27)$ & $460(23)$ & $551(25)$ & $340(36)$ & $419(26)$ & $506(27)$ \\
\hline \multicolumn{7}{|c|}{ Crab density $\left(\left[\right.\right.$ no. $\left.\left.\times 10^{-2}\right] / \mathrm{m}^{2}\right)$} \\
\hline Instar 7-12 & $14.90(17.81)$ & $15.66(17.94)$ & $10.75(13.17)$ & $12.86(16.06)$ & $14.84(17.63)$ & $8.75(10.97)$ \\
\hline Instar 13-17 & $2.46(0.56)$ & $2.84(1.42)$ & $1.60(0.98)$ & $2.22(0.5)$ & 2.89 (1.65) & $1.41(0.98)$ \\
\hline Instar $18+$ & $3.87(0.29)$ & $2.30(0.2)$ & $1.34(0.11)$ & $3.09(0.44)$ & $1.94(0.23)$ & $1.03(0.1)$ \\
\hline \multicolumn{7}{|c|}{ Total mortality rate $\left(\left[\right.\right.$ no. $\left.\left.\times 10^{-4}\right] / \mathrm{h}\right)$} \\
\hline Instar $7-12$ & $9.14(7.12)$ & $8.16(5.11)$ & $12.11(19.65)$ & $9.49(9)$ & $8.37(5.31)$ & $11.65(22.6)$ \\
\hline Instar 13-17 & $1.90(1.42)$ & $7.31(3.16)$ & $9.30(5.13)$ & $2.27(1.64)$ & $8.24(3.78)$ & $9.90(6.55)$ \\
\hline Instar $18+$ & $0.81(0.68)$ & $2.46(1.83)$ & $2.13(1.85)$ & $1.01(0.87)$ & $2.64(2.05)$ & $2.36(2.24)$ \\
\hline
\end{tabular}

Notes: The default interaction distance corresponds to the value used in previous simulations, "small" corresponds to decreasing this distance by a factor of four, and "large" represents doubling it. All simulations were done using a short hypoxic duration.

cannibalism declined and resulted in higher individual survival rates. Explaining the greater individual survival under greater hypoxic extents is facilitated by examining the relationship of daily raw mortality rate from all causes $\left(\right.$ no. $\cdot \mathrm{m}^{-2} \cdot \mathrm{h}^{-1}$ ) against the associated density of $7-$ 12 instar crabs (Fig. 5). Based on Fig. 5, two things are evident. First, at densities $<0.2 \mathrm{crabs} / \mathrm{m}^{2}$, increasing hypoxic extent increased the raw rate of mortality since the curve shifts toward the $y$-axis indicating that at the same crab densities, the raw rate of mortality was higher at $60 \%$ than $15 \%$ hypoxic extent. Finally, increasing hypoxic extent decreased the average crab density over all raw rates of mortality at each hypoxic extent and also the average raw rate of mortality over all crab densities at each hypoxic extent. For 13-17 and 18+ instar crabs, no dramatic differences were evident (Appendix C: Figs. $\mathrm{C} 2$ and $\mathrm{C} 3$ ). Thus, based on Fig. 5 and Fig. C4 (in Appendix C) we conclude that, although 7-12 instar crabs died at lower raw rates of mortality at smaller hypoxic extents for densities within the range of 0 to 0.2 crabs $/ \mathrm{m}^{2}$, the overall lower average death rate at larger

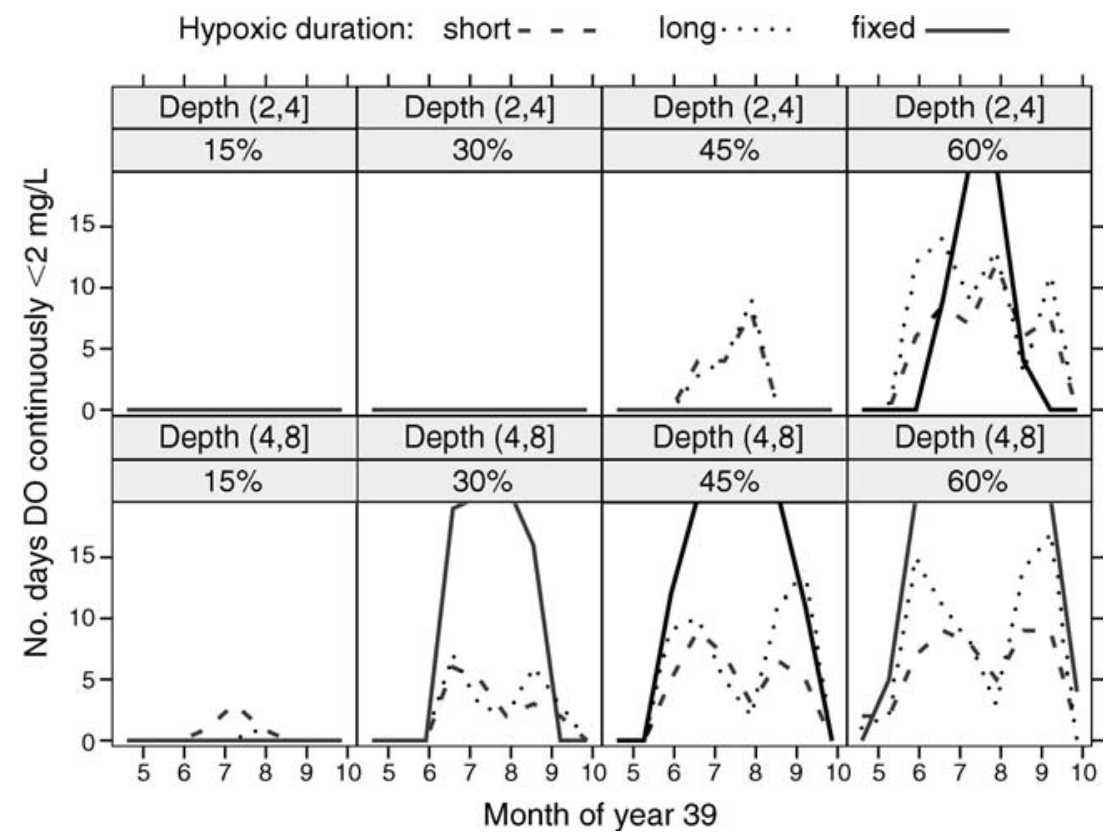

FIG. 4. Median number of days areas remain continuously hypoxic ( $\mathrm{DO}<2 \mathrm{mg} / \mathrm{L})$ in the model estuary (calculated across the fine-level triangles at depth intervals of 2-4 and 4-8 m) under the four hypoxic extents $(15 \%, 30 \%, 45 \%$, and $60 \%)$ for year 39 of the simulations. The number of consecutive days is calculated over consecutive, non-intersecting 20-day time windows. Under a fixed hypoxic duration, once an area becomes hypoxic at the start of summer it remains hypoxic until fall. However, since less than $50 \%$ of triangles at a given depth interval may be hypoxic at smaller hypoxic extents, the median number of hypoxic days can be zero. 
TABLE 3. Extended.

\begin{tabular}{|c|c|c|c|c|c|}
\hline \multicolumn{6}{|c|}{ Interaction distance } \\
\hline \multicolumn{3}{|c|}{$45 \%$ maximum hypoxia } & \multicolumn{3}{|c|}{$60 \%$ maximum hypoxia } \\
\hline Small & Default & Large & Small & Default & Large \\
\hline $\begin{array}{c}51(5) \\
272(27)\end{array}$ & $\begin{array}{l}146(7) \\
334(29)\end{array}$ & $\begin{array}{l}194(10) \\
397(29)\end{array}$ & $\begin{array}{c}32(3) \\
168(30)\end{array}$ & $\begin{array}{r}94(10) \\
190(25)\end{array}$ & $\begin{array}{l}129(10) \\
214(21)\end{array}$ \\
\hline $\begin{array}{c}10.22(12.17) \\
2.14(0.62) \\
2.62(0.25)\end{array}$ & $\begin{array}{c}11.06(13.46) \\
2.56(1.61) \\
1.45(0.21)\end{array}$ & $\begin{array}{l}6.89(8.57) \\
1.19(0.84) \\
0.74(0.08)\end{array}$ & $\begin{array}{l}2.98(4.03) \\
1.08(0.5) \\
1.44(0.26)\end{array}$ & $\begin{array}{l}4.08(5.07) \\
1.54(0.96) \\
0.76(0.14)\end{array}$ & $\begin{array}{l}3.37(4.33) \\
0.83(0.6) \\
0.45(0.07)\end{array}$ \\
\hline $\begin{array}{l}8.39(7.65) \\
3.05(2.09) \\
1.19(1.09)\end{array}$ & $\begin{array}{l}8.57(6.13) \\
8.89(4.47) \\
2.96(2.62)\end{array}$ & $\begin{array}{c}11.57(22.33) \\
10.29(7.96) \\
2.80(3.1)\end{array}$ & $\begin{array}{c}11.26(16.17) \\
3.17(3.01) \\
1.50(1.61)\end{array}$ & $\begin{array}{c}10.66(15.37) \\
8.32(5.12) \\
3.29(3.32)\end{array}$ & $\begin{array}{c}13.10(21.87) \\
10.51(15.53) \\
3.00(4.03)\end{array}$ \\
\hline
\end{tabular}

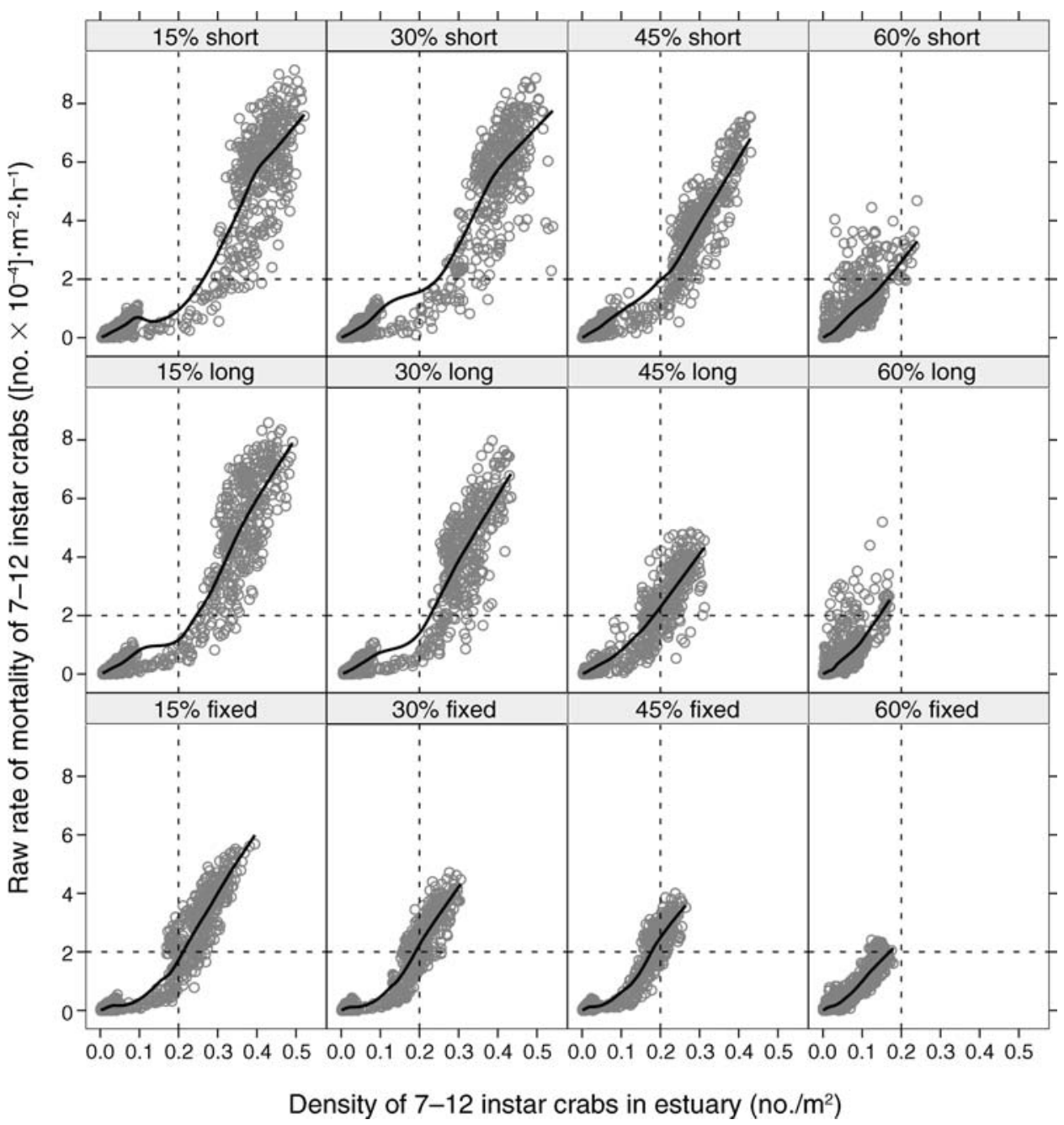

FIG. 5. Daily raw rates of mortality from all causes for 7-12 instar crabs relative to the density of 7-12 instar crabs in the estuary under hypoxic extents of $15-60 \%$, and of short, long, or fixed duration. The solid line was generated using a Loess smoother. The "bumps" at densities $<0.1 \mathrm{crabs} / \mathrm{m}^{2}$ occur due to combining the low density of 7-12 instar crabs that overwintered in the estuary with the high recruitment density of 7 instar crabs after the beginning of August. Densities $>0.2 \mathrm{crabs} / \mathrm{m}^{2}$ occurred primarily after mid-August as recruited crabs molted into higher instars and experienced inter-cohort cannibalism. 

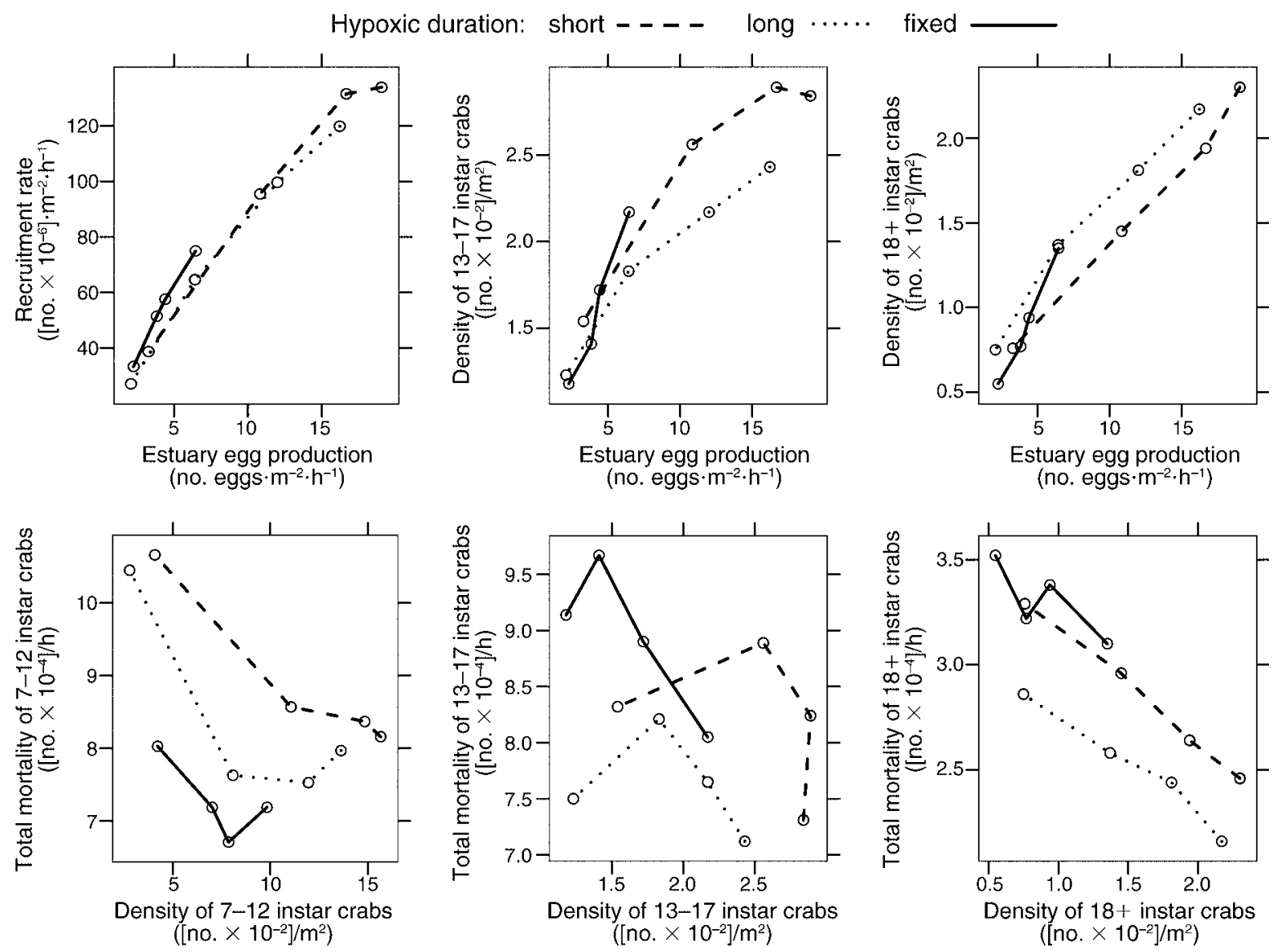

FIG. 6. The top row shows how crab recruitment rate for seventh-instar crabs and density of later-instar crabs scale relative to the overall rate of estuary egg production under the four hypoxic extents indicated (by the four points per line) for each hypoxic duration (short, long, and fixed). The bottom row shows how the rate of total mortality from all possible causes (aggression, starvation, senescence, and asphyxiation due to lack of oxygen) for 7-12,13-17, and 18+ instar crabs scales with crab density ([no. crabs $\left.\times 10^{-2}\right] / \mathrm{m}^{2}$ ). All values are averages of daily values over years $30-39$ of the simulations.

hypoxic extents (caused in part by lower average crab densities) lead to increased survivorship.

In addition to cannibalism, changes in crab egg production are an important part of the explanation of how crab population dynamics changed under increasing hypoxic extent. Increases in either maximum hypoxic extent or duration had substantial impacts on estuary egg production. Between 15\% and 60\% maximum hypoxic extents for short and long duration, estuary egg production decreased to $17 \%$ and $13 \%$ respectively, of the low hypoxic extent values; while under a fixed duration estuary egg production was decreased to $35 \%$ of this value. The low rates of egg production per crab under fixed duration relative to short or long duration were a result of the crabs' spatial distribution in the estuary. Under a fixed duration, essentially all the population was shallower than $3 \mathrm{~m}$ (Appendix C: Fig. C1), constraining crabs to warmer water. As a result, under current model assumptions (Appendix A: section A.5.5) crabs' respiration costs increased and less energy could be devoted to egg production. This hypothesis was confirmed by decreasing the average temperature of the estuary by $2^{\circ} \mathrm{C}$ under a fixed duration and observing that egg production increased. Thus, the regions between transient hypoxic patches serve as temperature refuges from warmer shoreline waters that crabs are forced into under fixed hypoxia.

Adult crab density is mainly explained by changes in mortality rates (driven by cannibalism) and egg production (Fig. 6). First, the rate of seventh-instar recruitment under fixed duration was slightly higher than under short or long durations at the same estuary rate of egg production. However, for a given rate of egg production, the density of $18+$ instar crabs was highest under long hypoxic duration. Second, the relationship between rates of total mortality (from all causes) to crab density changed across the instar classes. For example, for 7-12 instar crabs, fixed duration had the lowest total mortality rate at a given crab density, while for 13-17 and $18+$ instar classes, fixed generally had the highest total mortality rate at a given crab density. Thus, although egg production was the main factor limiting 

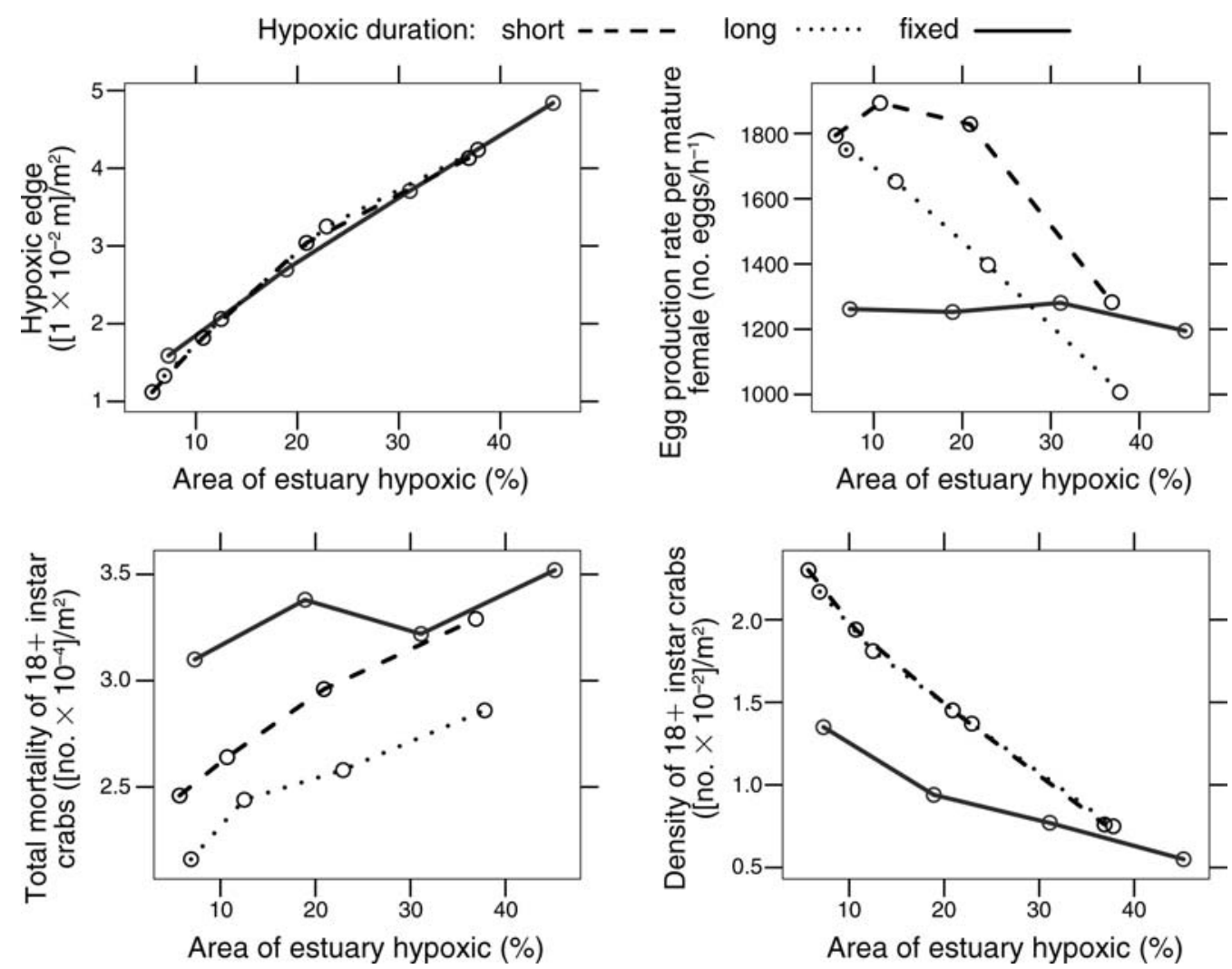

FIG. 7. Scaling of the amount of hypoxic edge (perimeter of area with $\mathrm{DO}<2 \mathrm{mg} / \mathrm{L}$ divided by the total area of the estuary), mean rate of egg production per mature female (no. eggs/h), total mortality rate ([no. crabs $\left.\times 10^{-4}\right] / \mathrm{h}$ ), and the density of $18+$ instar crabs ([no. crabs $\left.\times 10^{-2}\right] / \mathrm{m}^{2}$ ) plotted against the mean percentage of the estuary that is hypoxic. All values are averages over years $30-39$ of the simulations.

crab recruitment, cannibalism/patch interactions resulting from different hypoxic durations acted to alter population structure and dynamics.

We examined the effect transient vs. static patches have on crab population dynamics by accounting for the average percentage of the estuary hypoxic or unavailable to crabs (Fig. 7). The amount of hypoxic edge was not important. Transient patches gave higher rates of per female egg production (which decreased rapidly with increasing hypoxic extent) while under fixed hypoxia, egg production per mature female was constant. Total mortality rate for $18+$ instar crabs from all causes was ordered across average hypoxic extent according fixed $>$ short $>$ long due to an interaction between density and the raw rate of mortality. The density of $18+$ instar crabs under transient patches was up to 1.7 times higher than fixed duration, but decreased more rapidly than fixed with increasing average hypoxic extent.

\section{Scenario class II: altering prey availability}

Food limitation has been hypothesized as a primary factor limiting crab population dynamics. Thus, this scenario crossed three different levels of prey availability with four hypoxic extents under a Short hypoxic duration to explore how crab population dynamics differed under prey-limited and prey-unlimited conditions.

How does altering clam and background prey abundance affect crabs? - Within each hypoxic extent, background prey biomass was decreased to $\sim 33 \%$ of default under limited and increased to between $110 \%$ and $230 \%$ of default under unlimited (Table 2). Clam density (no./ $\mathrm{m}^{2}$ ) under prey limitation decreased to $\sim 50 \%$ of default or unlimited while clam biomass decreased to $\sim 40 \%$ of default under limited and increased to $\sim 120 \%$ to $300 \%$ of default under unlimited.

Differences in overall prey abundance (clams and background) altered crab density. Density of 7-12 instar crabs decreased to $50-64 \%$ of default under limited prey availability, while density under unlimited prey availability was $97 \%$ to $170 \%$ of default. A similar pattern occurred for 13-17 and 18+ instar crab density: decreasing prey availability lowered crab density, but increasing prey availability resulted in only small increases. Average crab biomass density decreased by $50 \%$ under prey limitation relative to default across all hypoxic extents and increased to $101 \%$ to $130 \%$ of default under unlimited prey. 

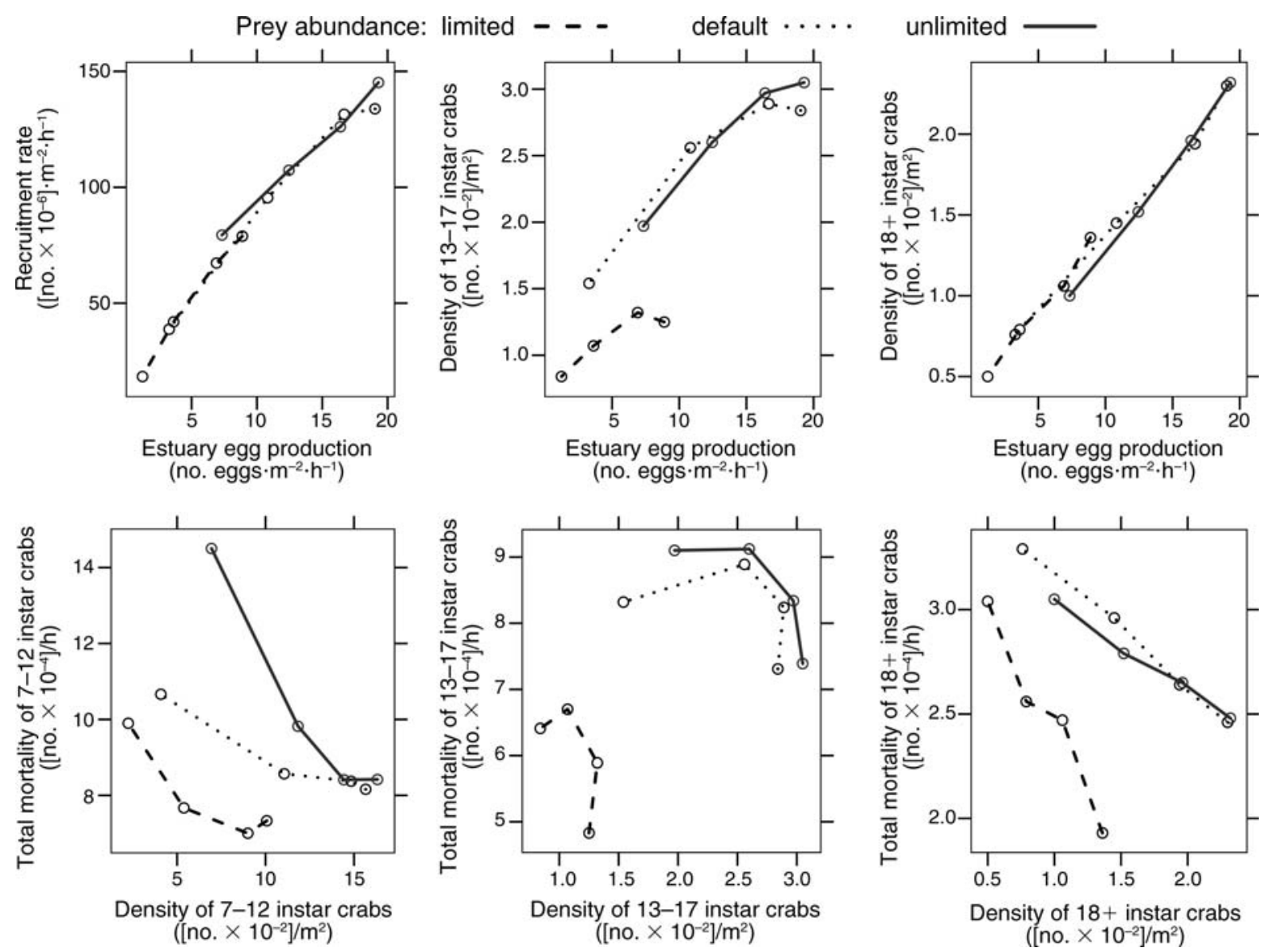

FIG. 8. Scaling of crab population variables under different levels of prey abundance. See Fig. 6.

What is the explanation for the differences in crab abundance? - We argue that, under prey limitation, crab population dynamics were primarily controlled by lower total rates of mortality (of which a large proportion was due to starvation), lower individual crab survival due to longer development times, decreased crab growth rates, and a reduction in the rate of egg production per mature female. Conversely, when prey was not limiting crab population dynamics were primarily controlled by the same mechanism operative under scenario I, density dependent cannibalism.

Relative to the rates of total mortality, mortality due just to aggression for 7-12 instar crabs accounted for $33 \%$ to $60 \%$ of the total mortality rate under prey limited conditions. Under default prey conditions and hypoxic extents of $45 \%$ or less, aggression accounted for $\sim 80 \%$ of 7-12 instar mortality and $90 \%$ under unlimited prey conditions. For 13-17 and 18+ instar crabs, aggression accounted for almost all crab mortality regardless of prey availability. At a given crab density, prey-limited 712 instar crabs had the lowest rate of total mortality, while prey-unlimited crabs had the highest total mortality rate (Fig. 8). The relationship of the total mortality to crab density varied between 13-17 and 18+ instars, but for a given crab density was lowest under limited (Fig. 8).

Although survival increased with increasing hypoxic extent (Fig. 9), at $15 \%$ hypoxic extent prey limited crabs had the lowest survival while at $60 \%$ hypoxic extent crabs with unlimited prey had the lowest survival. Part of the reason for the differences in crab survival was due to longer development times for crabs. Up to $20 \%$ of prey-limited crabs took longer than $1.2 \mathrm{yr}$ to reach sexual maturity (Fig. 10): an effect not seen with hypoxic extent and duration (Appendix C: Fig. C5). The increased time spent at lower instar classes decreased the survival of prey-limited crabs for hypoxic extents up to $45 \%$ beyond which their survival surpassed that of prey-unlimited crabs (Fig. 9).

The cause of the longer development times of preylimited crabs relates to their average gut fullness. For 712 instar crabs, average gut fullness was $\sim 0.66$ that of unlimited and the difference between default and unlimited at extents of $45 \%$ or less was small. A similar pattern held for 13-17 and 18+ instar crabs. Not only did prey limitation alter development times, it also decreased the overall rate of estuary egg production (no $\cdot \mathrm{m}^{-2} \cdot \mathrm{h}^{-1}$ ) to $37 \%$ to $80 \%$ of the default case. 


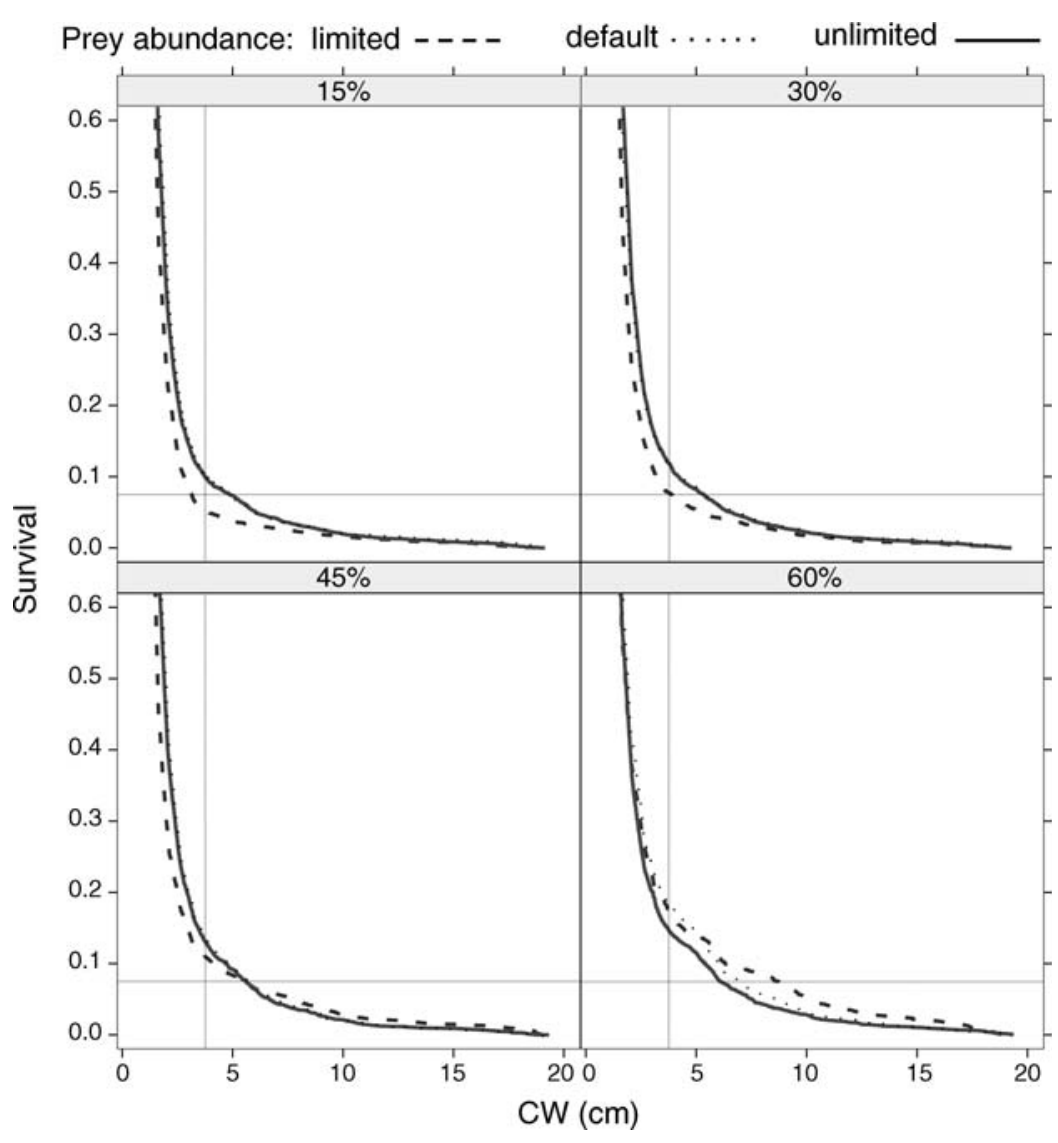

FIG. 9. Crab survival functions under altered prey availability. The food-limited case corresponds to decreasing the upper bound on clam biomass recruitment by one-half from its default value of $850 \mathrm{~g} / \mathrm{m}^{2}$ and decreasing the background prey carrying capacity by one-half from its default value of $400 \mathrm{~g} / \mathrm{m}^{2}$. The default value corresponds to the short hypoxic duration in scenario I. The prey-unlimited case corresponds to turning off all clam and background mortality due to hypoxia. A short hypoxic duration was used in all scenarios. Vertical and horizontal grid lines highlight the changes in the curves across the panels.

Although adult density was lower under prey limitation, egg production per mature female also decreased to $\sim 33 \%$ to $75 \%$ of the default simulation. However, controlling for the rate of estuary egg production, the rate of seventh and $18+$ instar recruitment was the same for all levels of prey availability (Fig. 8), while the density of 13-17 instar crabs was generally ordered according to default $>$ unlimited $>$ limited.

\section{Scenario class III: altering crab interaction distance and cannibalism potential}

Cannibalism-induced mortality is hypothesized as one major factor driving crab population dynamics and the previous scenarios supported this hypothesis. Thus, we examined how those dynamics changed when the potential for crab-crab cannibalism was altered.

How does altering crab cannibalism potential affect crab abundance, clams, and background prey?-Crab density showed large differences with varying degrees of crab cannibalism potential. Crab densities for 7-12 and 13-17 instar were highest under the default interaction distance, decreasing with increasing or decreasing cannibalism potential (Table 3). The highest density of $18+$ instar crabs occurred under the smallest cannibalism potential and decreased to $29 \%$ to $34 \%$ of these values under increased cannibalism potential while within each interaction distance the density of $18+$ instar crabs at high hypoxic extent was decreased to $33 \%$ to $37 \%$ of the low hypoxic extent values. Crab biomass behaved similarly to $18+$ crab density. The average background biomass under high cannibalism potential was $400 \%$ of the low cannibalism potential values (Table 3) while average clam biomass increased to $\sim 125-150 \%$ of the low potential values under high potential.

What is the explanation for the differences in crab abundance?-The differences in crab abundance under alternative cannibalism potentials resulted from changes in the rates of mortality, adult abundance, prey availability, rates of egg production per mature female, and the overall rate of estuary egg production. While the rate of mortality due to aggression increased with increasing cannibalism potential, mortality due to 


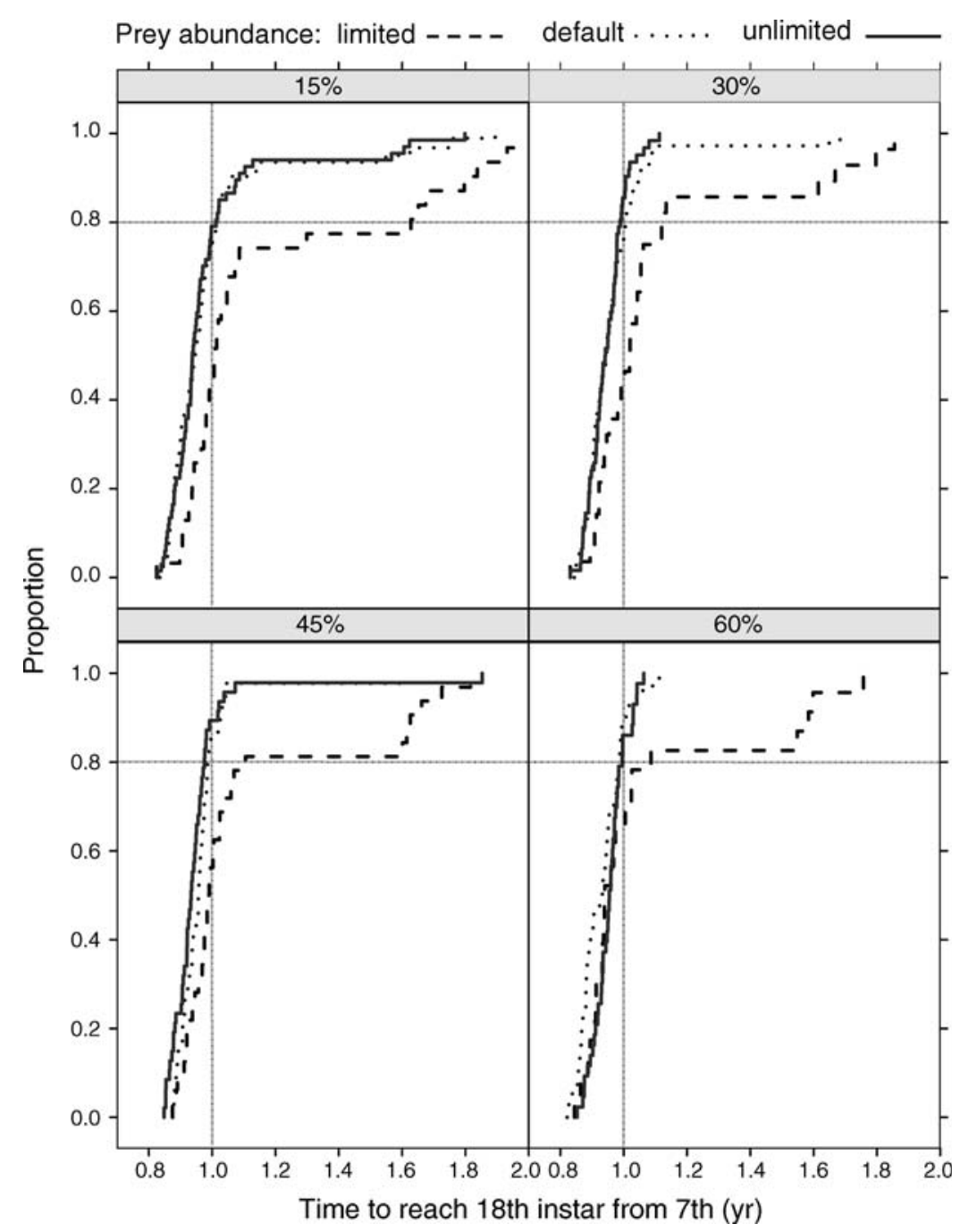

FIG. 10. Empirical cumulative distribution function for the time (years) it takes crabs under different levels of prey abundance (defined in Fig. 9) and hypoxic extents to reach the 18th instar from the seventh instar.

starvation decreased. The rate of mortality due to aggression for 7-12 instar crabs increased by a factor of $\sim 10$ with increasing interaction distance across all hypoxic extents while for 13-17 and 18+instar crabs the rate increased by factors of approximately four and two, respectively. The proportion of total mortality within each instar class accounted for by aggression also varied widely. For 7-12 instar crabs under the smallest interaction distance, only $6 \%$ to $16 \%$ of the total mortality was due to aggression and $\sim 62-85 \%$ was due to starvation. Under the default interaction distance, $54-91 \%$ of $7-12$ instar mortality was due to aggression $(<13 \%$ due to starvation) while under the largest interaction distances between $64 \%$ to $>99 \%$ was due to aggression ( $<3 \%$ due to starvation). The proportion of 13-17 and 18+ instar crabs dying from starvation was $<7 \%$ across all simulations while $75 \%$ of the mortality was due to aggression. For 7-12 instar crabs, total mortality at a given crab density was lowest under the smallest and default interaction distances while for 13-17 and 18+ instar crabs it was smallest for the smallest interaction distance (Fig. 11).

Across all hypoxic extents, the lowest survival for carapace widths $<10 \mathrm{~cm}$ occurred under the smallest interaction distance (i.e., lowest cannibalism potential), while the highest survival occurred under the default interaction distance (Appendix C: Fig. C6). Lower survival under lower cannibalism potential occurred because smaller carapace width crabs die from starvation at rates surpassing the reduction in mortality due to aggression. The extent of food limitation under the smallest cannibalism potentials is indicated by average gut fullness which was one-half that of default and large cannibalism potentials: a factor decrease exceeding that seen under scenario II. Further, under the smallest interaction distance, between $20 \%$ and $40 \%$ of crabs 

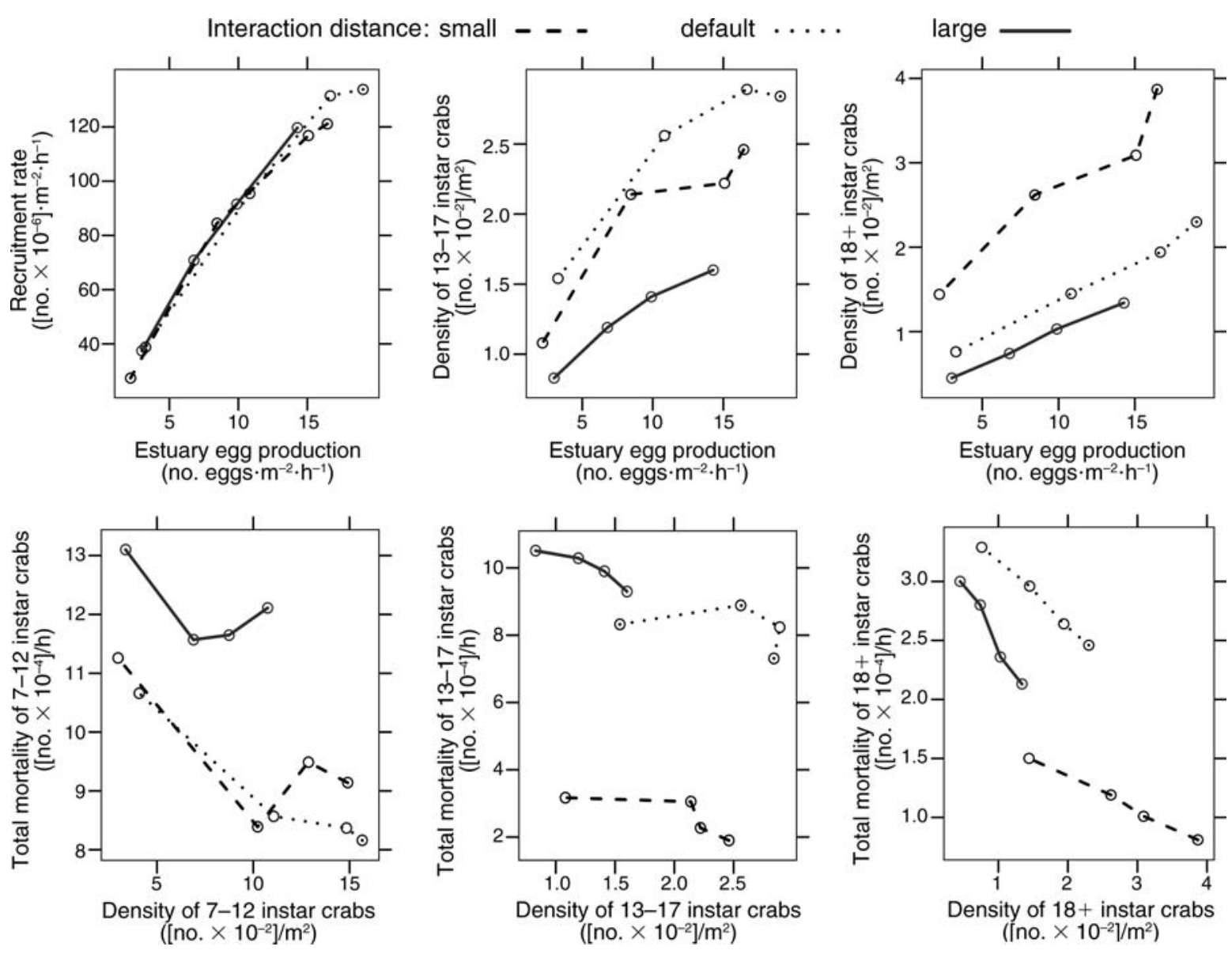

FIG. 11. Scaling of crab population variables under different interaction distances or cannibalism potentials. See Figs. 6 and 8.

took longer than $1.6 \mathrm{yr}$ to grow from the seventh to the 18 th instar, while under increased cannibalism potential, all crabs took less than a year (Fig. 12).

The primary factor limiting seventh-instar recruitment was the rate of egg production in the estuary (Fig. 11). Between the small and large interaction distances within each hypoxic extent, the relative increase in egg production per mature female increased from $225 \%$ at $15 \%$ hypoxic extent to $500 \%$ at $60 \%$ (Appendix C: Table C4). However, the lower estuary egg production rates under decreasing or increasing cannibalism potentials were caused by two quite different mechanisms. Decreasing cannibalism potential resulted in higher adult crab densities which induce food limitation resulting in a low rate of egg production per mature female crab which in turn lead to a net decrease in the rate of estuary egg production. Alternatively, increasing cannibalism potential removed the food limitation so that each mature female crab produced more eggs; however, the increased cannibalism potential lowered adult crab densities so much that the net rate of estuary egg production also decreased.

\section{Discussion}

\section{Summary: transient vs. static patches}

The scenarios presented in Results explored two related questions: (1) Do transient patches affect blue crab populations in the same manner as static patches? (2) Are changes in crab population dynamics caused primarily by increased cannibalism or food limitation? With respect to the first question, the population controls operating under transient patches differ from those operating under static patches. Transient patches result in higher local densities of crabs due to avoidance of low DO and greater encounter rates of crabs, increasing the chance of cannibalism (e.g., movies in Appendix E, Fig. B12 in Appendix B). This cannibalism $\times$ patch interaction leads to local density-dependent controls over the population. In contrast, under static patches, lower female egg production (due to crabs spending more time in warmer waters) is the primary factor limiting the population.

In examining the mechanisms behind the population dynamics produced by the model, the patterns of average gut fullness, survival, sources of mortality and crab 


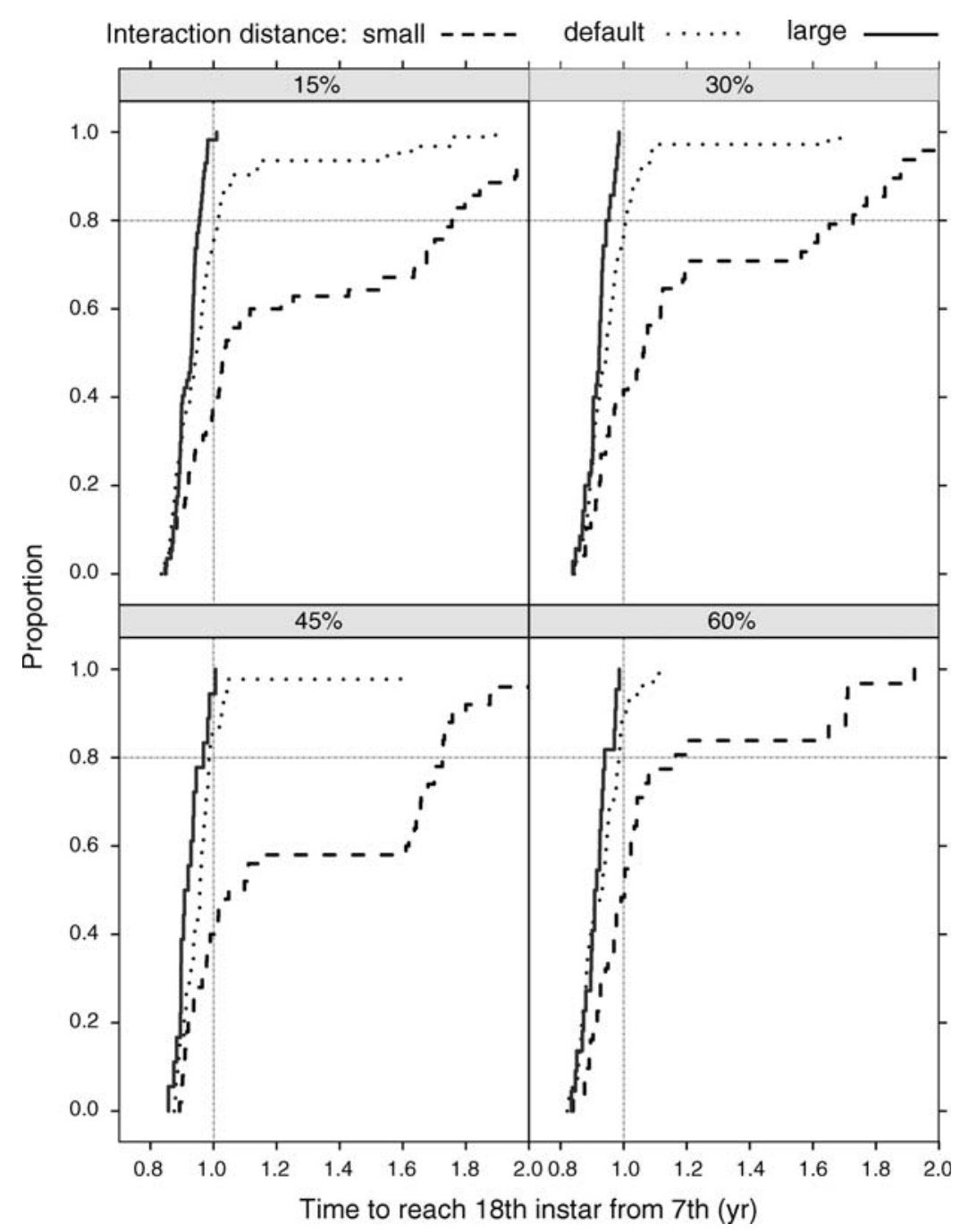

FIG. 12. Empirical cumulative distribution function for the time it takes crabs under different crab-crab interaction distances or cannibalism potentials and hypoxic extents to reach the 18 th instar from the seventh instar.

development times under the different hypoxic extents all indicate that food limitation is not the primary mechanism regulating crab population dynamics in either transient or static patches. Under food limitation (e.g., the resource conditions achieved by decreasing prey abundance by one-half) gut fullness decreases, survival decreases, starvation becomes an important source of mortality, and development times increase. From a population perspective, the model also shows that "moderate" degrees of cannibalism are beneficial relative to lower rates of cannibalism because "moderate" rates eliminate the higher mortality rates and lower per crab egg production rates associated with food limitation. Alternatively, larger degrees of cannibalism, while beneficial in terms of egg production by individual mature females, lead to lower adult densities and also lower estuary egg production rates. These findings of a net population benefit for cannibalism are in agreement with those suggested by Polis (1981) and observed in an ecophysiological population model of development in praying mantids (Fagan and Odell 1996).

Even though there are challenges in studying ecological problems related to transient patches, such as difficulties in assessing the role of such changing conditions on demographic rates and analyzing models with time-varying parameters, we should not ignore such systems. Indeed, several recent studies have identified situations in which the abiotic characteristics of patches change on fast time scales and have profound impacts on species population dynamics. Episodic, pulse-like events, such as changes in temperature, rainfall, or fires can also have the effect of creating transient conditions. For example, temporal variation in snow hardness may influence the well-known hare-lynx predator-prey cycles (Stenseth et al. 2004). In mesic grasslands, exposure to fewer, larger rainfall events 
reduces above ground net primary production relative to ambient rainfall patterns even when total precipitation amount is held constant (Knapp et al. 2002), while the beetle Melanophila acuminata De Geer is so dependent on freshly killed trees that it responds to short-lived emissions of infrared radiation from fires up to $20 \mathrm{~km}$ away (Evans 1966).

Biotic characteristics of patches can be just as transitory as abiotic characteristics. Perhaps the most broadly studied of such scenarios involve the narrow "windows of opportunity" that many early successional dependent species rely upon. For example, the Blackbacked Woodpecker (Picoides arcticus) and Northern Hawk Owl (Surnia ulula) both only inhabit burns for a few years following a major fire (Hutto 1995, Hoyt and Hannon 2002, Hannah and Hoyt 2004). Arthropods that breed in discrete, ephemeral, patchily distributed resources ("DEP" systems such as carrion, fruit, dung, or wood) have received considerable attention from ecologists because such transient patches facilitate the coexistence of multiple species (Atkinson 1981, Hanski 1987, Ives 1988, Shorrocks and Bingley 1994, Jordal and Kirkendall 1998). Colonization sequence can be critically important in many transient patch systems, because early arrivals may modify local conditions biochemically, structurally, or by altering food web dynamics (Wilbur 1997).

The estuarine hypoxic patches emphasized here that form and disappear in a matter of hours to weeks are far more transitory than even the "short-lived" patches that are the focus of studies in successional or DEP systems. Consequently, our study on crabs is best placed at the highly dynamic end along a continuum of models exploring the issues of patch duration or turnover rate (e.g., Paine and Levin 1981, Caswell and Cohen 1991, Gyllenberg and Hanski 1997, Johnson 2000).

The field studies previously cited demonstrate examples of both abiotic and biotic transient patches influencing populations and communities through similar mechanisms as static patches. Specifically, the creation of novel, diverse, and/or patchy resources can alter predator prey and competitive interactions. In addition, the alteration of these interactions appears to allow the coexistence of multiple species in DEP systems and potentially alters the mechanisms regulating population dynamics as demonstrated in the current model. We suspect that transient patch phenomena are likely important in many different systems, but the handful of disparate case studies available at present makes it challenging to answer the important question of "when" transient patch phenomena will be of critical importance in altering behavior, habitat use, or species interactions to the extent that population dynamics are changed.

\section{Model assumptions and experiments needed}

While the high level explanations given for model behaviors under the three different scenarios are internally consistent, gaps in our knowledge about various aspects of the model prevent us from inferring which of these explanations are most relevant to crab populations in estuaries. A number of such knowledge gaps were identified during model synthesis (Appendix A) and are presented here relative to their perceived priority for increasing our understanding of crab population dynamics.

The nature of crab-crab interactions. - Crab-crab cannibalism is a key uncertainty in this otherwise wellstudied system. Although we are able to provide empirical justification for almost all other model assumptions (see Appendix A), little justification could be given for the behavioral details of crab-crab interactions (Appendix A: section A.5.3). Given that the results show how the degree of cannibalism between crabs can lead to a population that is either food limited or structured by the effects of cannibalism, greater experimental effort needs to be directed at increasing knowledge about the nature of crab-crab cannibalism if we are to have confidence about the factors controlling crab population dynamics.

Specific questions that should be addressed through empirical study include: (1) Given that crabs of sizes $s_{1}$ and $s_{2}$ spend $x \%$ of their time within a distance $y$ of each other, what is the probability that the crab of size $s_{1}$ was cannibalized? (2) Is this probability invariant under different size ratios of the crabs? (e.g., carapace width of 2 vs. $4 \mathrm{~cm}$ and 4 vs. $8 \mathrm{~cm}$ ). Knowing the answers to these two questions for a population of praying mantises proved key to unraveling the importance of sizedependent cannibalism in that system (Fagan and Odell 1996). A third key question for intermolt crabs is whether the probability of cannibalism increases linearly with the number of crab-crab interactions across different crab size ranges or whether other factors are involved. Finally, it should be determined whether there is sexual bias in blue crab cannibalism. For 50 species where sexual differences of the predator were noted, $86 \%$ of the females were more cannibalistic than males and males were eaten more frequently by females in $76 \%$ of 45 species (Polis 1981). Answering all these questions empirically for crabs is not easy, but the model clearly demonstrates how increased knowledge of crab-crab cannibalism would increase our understanding of crab population dynamics at the estuary scale.

Crab energy balance.-Relative to most species, a great deal is known about crab energy balance. However, the results of the three scenarios also show how crucial the assumptions about energy balance are to the actual population dynamics observed. The rate of adult egg production is directly related to energy balance, which in turn sets an upper bound on crab recruitment thereby limiting subsequent adult abundance. For example, a fixed hypoxic duration in the first scenario leads to a lower rate of crab egg production because the crabs are in warmer water that (under the modeling assumptions made) decreases the amount of energy available for egg production. Greater knowledge 
of crab physiology would reduce the uncertainty associated with applying the model results to crab populations in actual estuaries. Thus, further empirical studies aimed at quantifying crab energy usage (e.g., respiration, movement, molting) across wide temperature and salinity ranges for different sized crabs are needed. In addition, we need to know how egg production is altered under food limitation or when females have lost $x \%$ of their mass.

Effect of hypoxia on clams and background prey.Although little is known about how hypoxia alters clams and background prey, under current model assumptions, we do not think refined data on this issue would have a major impact on our understanding of crab population dynamics. The survival function for exposure to DO (Appendix A: section A.4.2) is obtained using Bayesian expert elicitation techniques (Borsuk et al. 2002). Using parameter values from the tails of the resulting posterior distribution to assess the sensitivity of the crab population to these assumptions (Appendix B: section B.3.2), we found little effect of clam (or background) survival on crab abundance relative to altering hypoxic extent and duration (scenario I), or cannibalism potential (scenario III).

Other known model limitations.-Despite the detailed nature of this model, it includes a number of implementation decisions that are oversimplifications. Uncertainty about the nature of crab cannibalism meant that the potential for cannibalism is only decreased if the attacking crab's gut is full and is not decreased by depth or by crabs seeking out habitat refuges. These limitations are presently all "rolled up" into the particular assumptions made about crab-crab cannibalism (Appendix A: section A.5.3).

It is known that crabs about to molt seek out more structurally complex habitats to decrease their risk of predation and that the risk of predation in unstructured habitats varies spatially across the estuary (Lipcius et al. 2005). However, the model does not represent such complex habitats nor is any reduction in mortality risk applied to molting crabs. Thus, although the cumulative time a crab spends molting during is lifetime is small, cannibalism during molting is likely more frequent in the model than in actual estuaries.

Another model limitation ignores the part of the crab life cycle from recruitment (megalopae stage) to the sixth instar, yet all model scenarios showed how important cannibalism and food limitation are at the lower instar stages for setting overall population dynamics. The decision not to model these earlier instar classes was guided by pragmatic considerations about computation time and a lack of knowledge about these early life stages. For example, it is not known if the particular assumptions made about energy balance or cannibalism for $7+$ instar crabs hold over instars 1 to 6 . While the model suggests that early life stages are very important for population dynamics, the experiments needed to increase the knowledge of these early life stages are likely even more difficult than those required for later instars.

We made assumptions regarding the clam population using a different geographic area due to the availability of published work. Some differences with the clam population in the Neuse River Estuary included (1) the life history characteristics of the clams differed from those used in the model (size of clams at maturity and when spawning occurred), (2) clam densities in the model were at the high end and crab densities at the low end of those observed empirically, and (3) clam recruitment was too low in shallow parts of the estuary. When these model assumptions were changed (as detailed in section B.5 of Appendix B), the conclusion was that even though the clam part of the model may be misspecified with respect to the Neuse, this had no impact on the scientific inferences made.

We see modeling as a cyclic processes involving synthesis, critique and directed experimentation aimed at challenging model assumptions and predictions (Ford 2000). Thus, we hope that more model assumptions and predictions will be experimentally challenged in the future so that the utility of this model will extend beyond questions of food-limitation vs. cannibalism to providing guidance for management. Because we will never have complete autoecological understanding of the systems we model, we do not see the progressive synthesis process converging to some "truth." Instead, the outcome of this process are models (and thus theories) with more explanatory power because the model "is like" the source system in more ways as judged using ever larger sets of assessment criteria.

Experiments to assess model predictions.-Under the current modeling assumptions, one of the central predictions made is that large decreases in clam and background prey can occur from hypoxia without these decreases causing crab food limitation and limiting the crab population. In the model, guts of food-limited crabs were only half as full as non-food-limited crabs while food quality (computed for crabs that had nonempty guts) showed no change. If crabs in an estuary are food-limited, then this should be reflected in the average gut fullness of crabs and also the average caloric content of the food in their guts. Sampling crabs over a year and analyzing how gut fullness and food quality change through time in estuaries experiencing little vs. severe hypoxia would provide important insights into this basic question. However, we are not aware of any studies that have measured gut fullness continuously over time in East Coast estuaries.

The model also suggests that another indicator of food limitation is the rate of egg production per mature female. Scenarios II and III in which food limitation is induced indicate that egg production per mature female decreases to $50 \%$ to $30 \%$ of the food unlimited cases. Although estimating both adult abundance and the rate of egg production in an estuary is not easy, the large magnitude of changes predicted may make such an 
indicator possible. Similarly, food limitation should also be reflected in the time required to reach sexual maturity. It should be noted that our model suggests that adult abundance is a poor indicator of foodlimitation in blue crabs. Decreased cannibalism potential produces a high density of food-limited adults (Table 3), whereas decreased prey abundance (Table 2) gives low densities of food-limited 18+ instar crabs, which have starkly different implications for subsequent recruitment potential.

\section{Steps toward the unification of population and ecosystem perspectives in estuarine ecology}

A central question in ecology is whether a particular descriptive scale exists which will enable us to capture the main dynamics of an ecosystem (Levin 1992, Pascual and Levin 1999). The assumption that such scales exist is central to the hierarchical patch dynamics framework used in landscape ecology (Wu and Loucks 1995, Wu and David 2002). Transient hypoxic patches certainly highlight the difficulties of robustly defining such patches and scales. In addition, transient hypoxia also identifies key problems associated with the mismatch between rapidly changing patches and slower changing crab population dynamics. Instead of utilizing such an approach, our approach to capturing dynamics in this estuarine system is to decompose the system hierarchically into scalar levels (lower levels contained within higher levels), with each level defined by the existence of emergent properties which arise out of the properties and relations characterizing simpler constituents but are neither predictable from, nor reducible to, these lowerlevel characteristics (Kim 1995, Rasmussen et al. 2001). Ecological examples of what we mean by emergent properties include, for example, the multifaceted behaviors and properties of coral reefs (Hatcher 1997), multiple predator effects (Harvey et al. 2004), and the induction of cannibalistic giants in piscivorous fish (Claessen et al. 2000, Persson et al. 2004).

Our approach to modeling this estuarine system also encompasses a number of distinct ecological perspectives. For example, including detailed physiological processes at the lowest hierarchical levels allows the model to encompass aspects of physiological ecology. By including complete life cycles and focusing on the mechanisms altering abundance, natality, and mortality of the population, it embraces central principles of population ecology. Since individuals (and their components) exchange matter, energy, and information within a spatially explicit context, the model also encompasses an ecosystem perspective. Historically, each of these perspectives (and others) have been used singly to try and address central questions in ecology (Cooper 2003: chapter 2), but each perspective has its own set of strengths and weaknesses. For example, physiological ecology generally focuses on abiotic environmental factors, while models in population ecology generally oversimplify life cycles, ignore dynamics of resources (e.g., food, habitat quality, space), and ignore individual variability (Uchmanski and Grimm 1996). Many individual-based models also suffer from the same limitations (Grimm 1999). Meanwhile at the upper levels of the hierarchy, ecosystem ecology contains an underlying tension between holism and reductionism (Cooper 2003: Chapter 2). On the one hand, ecosystem ecology maintains that understanding any part of an ecological community requires grasping the entire biotic and abiotic system (and thereby coming to grips with the problem of emergentism), yet in its approach it reduces the entire ecosystem to energy flow, nutrient exchange, or some other single measure (Mansson and McGlade 1993). Bridging the gulf between population and ecosystem ecology requires addressing all of these issues.

Hierarchy theory is an organizational principle which has proven useful for organizing and understanding complex systems (O’Neill et al. 1986, Salthe 1993). Hierarchies are not found in nature, but instead we construct nature hierarchically (Salthe 1985). This idea is central to much of landscape ecology (e.g., Golley 1987, O’Neill 1989, Wu 1999). Hierarchy theory, however, has had little impact on population ecology. Part of the reason for this lack of influence is that in the particular version of hierarchy theory influential in landscape ecology (e.g., O’Neill et al. 1986, Wu and Loucks 1995), the different levels are defined primarily by differences in rates (O'Neill and King 1998). However, this criteria is difficult to apply to organisms and populations that are composed of many different rate processes, especially if one is concerned about the reality value of the entities composing the hierarchical levels. We propose that basing a scalar hierarchical decomposition on emergent properties resolves these problems.

As an example, consider explaining the purpose of crab-crab cannibalism in scenario III. From a strict population ecology perspective this is difficult because spatial population models can only predict how population dynamics change under alternative population-level assumptions about the effects of cannibalism on recruitment and mortality. Further complications arise if we also want to consider the population dynamics in a broader context which includes multiple environmental and resource variables. However, simply resorting to an IBM is not necessarily sufficient either because, as Grimm (1999) notes, less than half of all IBMs produce transgenerational population dynamics, take resources into account, describe resource dynamics or allow individual variability. The problem is that typical spatial population ecology models lack linkages to the individual level making it difficult to determine how alternative environmental and resource conditions change population controls. IBMs, however, generally lack sufficient realism either because they ignore lowerlevel constraints imposed by metabolism or the higherlevel context provided by resources and environmental variables. Population ecology would benefit by embrac- 
ing hierarchy theory because hierarchy theory provides such levels.

Utilizing hierarchy theory in which the levels are characterized by emergent properties also resolves the underlying tension between holism and reductionism in ecosystem ecology. Explanation of behavior at a given hierarchical level utilizes both the higher and lower hierarchical levels without relying solely on lower levels or reducing the processes in the ecosystem to a single currency. For example, to explain why and how crab population dynamics (e.g., the emergent behavior of the relationships between the aggregate measures defined over all individual crabs in the estuary) change under different hypoxic patch types requires consideration of such factors as how hypoxic patches cause individual crab displacements, thereby altering individual crab's energy usage, crab cannibalism, and the effect of such patches on the benthos. This explanation utilizes both higher level environmental variables and lower level physiological variables while still respecting the nonreducibility of the entities appearing in the explanation. The explanation cannot be constructed solely using energy, individual crab-level behaviors or lower-level crab physiology. Thus, any claim of reductionism fails. However, because each level is defined by emergent properties we are still respecting the holistic perspective embraced by ecosystem ecology. Importantly, the approach is holistic without side-stepping the problem of emergence (Bergandi and Blandin 1998).

In summary, the detailed empirical information on crab behavior, development, physiology, and ecology and the long history of basic and applied research in this system allowed us to construct a highly detailed model spanning the physiological, population, and ecosystem perspectives. Structuring the model according to scalar hierarchy theory so that each level is characterized by emergent properties enabled us to show that crab population dynamics can only be explained using both higher (ecosystem) and lower (physiological) hierarchical levels. The underlying unity, realism, and explanatory power of this framework suggests it may be one way to unify population and ecosystem perspectives in estuarine ecology.

\section{ACKNOWLEDGMENTS}

We thank Margaret Palmer, Denise Breitburg, Larry Crowder, and Eric Johnson for sharing their insights about estuarine systems with us. Volker Grimm, Thomas Miller, and one anonymous reviewer provided insightful and constructive critiques that greatly improved this manuscript. We appreciate their investment in this manuscript and appendices. Finally, we extend a very big "Thank you!" to Anson "Tuck" Hines at the Smithsonian Environmental Research Center for many hours of patient assistance and for sharing with us a number of in press and unpublished articles.

\section{Literature Cited}

Atkinson, W. 1981. An ecological interaction between citrusfruit, penicillium molds and Drosophila immigrans Sturtevant (Diptera, Drosophilidae). Ecological Entomology 6:339-344.
Balci, O. 1994. Validation, verification, and testing techniques throughout the life cycle of a simulation study. Annals of Operations Research 53:121-173.

Bergandi, D. 2000. Eco-cybernetics: the ecology and cybernetics of missing emergences. Kybernetes 29:928-942.

Bergandi, D., and P. Blandin. 1998. Holism vs. reductionism: do ecosystem ecology and landscape ecology clarify the debate? Acta Biotheoretica 46:185-206.

Borsuk, M., S. Powers, and C. Peterson. 2002. A survival model of the effects of bottom-water hypoxia on the population density of an estuarine clam (Macoma balthica). Canadian Journal of Fisheries and Aquatic Sciences 59:1266-1274.

Breitburg, D., L. T. Loher, and C. Pacey. and A.Gerstein. 1997. Varying effects of low dissolved oxygen on trophic interactions in an estuarine food web. Ecological Monographs 67: 489-507.

Buzzelli, C. P., R. A. Luettich, Jr., S. P. Powers, C. H. Peterson, J. E. McNinch, J. L. Pinckey, and H. W. Paerl. 2002. Estimating the spatial extent of bottom-water hypoxia and habitat degradation in a shallow estuary. Marine Ecology Progress Series 230:103-112.

Caswell, H., and J. E. Cohen. 1991. Disturbance, interspecific interaction, and diversity in metapopulations. Biological Journal of the Linnean Society 42:193-218.

Claessen, D., A. de Roos, and L. Persson. 2000. Dwarfs and giants: cannibalism and competition in size-structured populations. American Naturalist 155:219-237.

Commito, J. A. 1982. Effects of Lunatia heros predation on the population dynamics of Mya arenaria and Macoma balthica in Maine, USA. Marine Biology 69:187-193.

Cooper, G. J. 2003. The science of the struggle for existence: on the foundations of ecology. Cambridge University Press, New York, New York, USA.

Craig, J. K., L. B. Crowder, C. D. Gray, C. J. McDaniel, T. A. Henwood, and J. G. Hanifen. 2001. Ecological effects of hypoxia on fish, sea turtles, and marine mammals in the northwestern Gulf of Mexico. Pages 269-291 in N. N. Rabalais and R. E. Turner, editors. Coastal hypoxia: consequences for living resources and ecosystems. No. 58. Coastal and Estuaries Studies. American Geophysical Union, Washington, D.C., USA.

Das, T., and W. B. Stickle. 1993. Sensitivity of crabs Callinectes sapidus and $C$. similis and the gastropod Stramonita haemastoma to hypoxia and anoxia. Marine Ecology Progress Series 98:263-274.

Das, T., and W. B. Stickle. 1994. Detection and avoidance of hypoxic water by juvenile Callinectes sapidus and $C$. similis. Marine Biology 120:593-600.

Diaz, R. J., and R. Rosenberg. 1995. Marine benthic hypoxia: a review of its ecological effects and the behavioral responses of benthic macrofauna. Oceanography and Marine Biology: an Annual Review 33:245-303.

Eggleston, D. B. 1998. Population dynamics of the blue crab in North Carolina: statistical analyses of fisheries survey data. Technical report. North Carolina State University, Department of Marine, Earth and Atmospheric Sciences, Raleigh, North Carolina, USA.

Epifanio, C. E. 1995. Transport of blue crab (Callinectes sapidus) larvae in the waters off mid-Atlantic states. Bulletin of Marine Science 57:713-725.

Evans, W. G. 1966. Perception of infrared radiation from forest fires by Melanophila acuminata De Geer (Buprestidae, Coleoptera). Ecology 47:1061-1065.

Fagan, W. F., R. S. Cantrell, and C. Cosner. 1999. How habitat edges change species interactions. American Naturalist 153: $165-182$.

Fagan, W. F., and G. M. Odell. 1996. Size-dependent cannibalism in praying mantids: using biomass flux to model sizestructured populations. American Naturalist 147:230-268.

Ford, E. D. 2000. Scientific method for ecological research. Cambridge University Press, New York, New York, USA. 
Gilbert, M. A. 1978. Aspects of the reproductive cycle in Macoma balthica (bivalvia). Nautilus 92:21-24.

Golley, F. B. 1987. Introducing landscape ecology. Landscape Ecology 1:1-3.

Grimm, V. 1999. Ten years of individual-based modelling in ecology: what have we learned and what could we learn in the future? Ecological Modelling 115:129-148.

Gyllenberg, M., and I. Hanski. 1997. Habitat deterioration, habitat destruction, and metapopulation persistence in a heterogeneous landscape. Theoretical Population Biology 52: 198-215.

Hannah, K. C., and J. S. Hoyt. 2004. Northern Hawk Owls and recent burns: does burn age matter? Condor 106:420-423.

Hanski, I. 1987. Carrion fly community dynamics: patchiness, seasonality and coexistence. Ecological Entomology 12:257266.

Hanski, I., and M. E. Gilpin, editors. 1997. Metapopulation biology: ecology, genetics, and evolution. Academic Press, San Diego, California, USA.

Harvey, B. C., J. L. White, and R. J. Nakamoto. 2004. An emergent multiple predator effect may enhance biotic resistance in a stream fish assemblage. Ecology 85:127-133.

Harvey, M., and B. Vincent. 1989. Spatial and temporal variations of the reproductive cycle and energy allocation of the bivalve Macoma balthica (L.) on a tidal flat. Journal of Experimental Marine Biology and Ecology 129:199-217.

Hatcher, B. G. 1997. Coral reef ecosystems: how much greater is the whole than the sum of the parts? Coral Reefs 16:S77S91.

Heck, K. L., Jr., and L. D. Coen. 1995. Predation and the abundance of juvenile blue crabs: a comparison of selected east and gulf coast (USA) studies. Bulletin of Marine Science 57:877-883.

Hines, A. H., and G. M. Ruiz. 1995. Temporal variation in juvenile blue crab mortality: nearshore shallows and cannibalism in Chesapeake Bay. Bulletin of Marine Science 57: 884-901.

Honkoop, P. J. C., J. van der Meer, J. J. Beukema, and K. Kwast. 1998. Does temperature-influenced egg production predict the recruitment in the bivalve Macoma balthica? Marine Ecology Progress Series 164:229-235.

Hoyt, J. S., and S. J. Hannon. 2002. Habitat associations of Black-backed and Three-toed Woodpeckers in the boreal forest of Alberta. Canadian Journal of Forest Resources 32: 1881-1888.

Hutto, R. L. 1995. Composition of bird communities following stand-replacement fires in northern rocky mountain (U.S.A.) conifer forests. Conservation Biology 9:1041-1058.

Ives, A. R. 1988. Aggregation and coexistence of competitors. Annales Zoologici Finnici 25:75-88.

Jachowski, R. L. 1974. Agonistic behavior of the blue crab, Callinectes sapidus Rathbun. Behaviour 50:232-253.

Johnson, M. P. 2000. Temporally explicit habitat ecology and the coexistence of species. Proceedings of the Royal Society of London B 1456:1967-1972.

Johst, K., R. Brandl, and S. Eber. 2002. Metapopulation persistence in dynamic landscapes: the role of dispersal distance. Oikos 98:263-270.

Johst, K., R. Brandl, and R. Pfeifer. 2001. Foraging in a patchy and dynamic landscape: human land use and the White Stork. Ecological Applications 11:60-69.

Jordal, B. H., and L. R. Kirkendall. 1998. Ecological relationships of a guild of tropical beetles breeding in Cecropia petioles in Costa Rica. Journal of Tropical Ecology 14:153176.

Kim, J. 1995. Emergent properties. Page 224 in T. Honderich, editor. The Oxford companion to philosophy. Oxford University Press, Oxford, UK.

Knapp, A. K., P. A. Fay, J. M. Blair, S. L. Collins, M. D. Smith, J. D. Carlisle, C. W. Harper, B. T. Danner, M. S. Lett, and J. K. McCarron. 2002. Rainfall variability, carbon cycling, and plant species diversity in a mesic grassland. Science 298:2202-2205.

Krebs, C. J. 1995. Two paradigms of population regulation. Wildlife Research 22:1-10.

Levin, S. A. 1992. The problem of pattern and scale in ecology. Ecology 73:1943-1967.

Lipcius, R. N., R. D. Seitz, M. S. Seebo, and D. Colón-Carrión. 2005. Density, abundance and survival of the blue crab in seagrass and unstructured salt marsh nurseries of Chesapeake Bay. Journal of Experimental Marine Biology and Ecology 319:69-80.

Lowery, T. A., and L. G. Tate. 1986. Effect of hypoxia on hemolymph lactate and behavior of the blue crab Callinectes sapidus Rathbun in the laboratory and field. Comparative Biochemistry and Physiology 85A:689-692.

Luettich, R. A., Jr., C. S. Martens, J. E. McNinch, H. W. Paerl, J. L. Pinckney, C. H. Peterson, M. Alperin, and J. T. Wells. 1999. Neuse river estuary MODeling and MONitoring project: monitoring phase. Technical Report Draft 4. Institute of Marine Sciences, University of North Carolina, Morehead City, North Carolina, USA.

Mansson, B. A., and J. M. McGlade. 1993. Ecology, thermodynamics and H. T. Odum's conjectures. Oecologia 93:582-596.

Miller, T. J. 2003. Incorporating space into models of the Chesapeake Bay blue crab population. Bulletin of Marine Science 72:567-588.

Mooij, W. M., R. E. Bennetts, W. M. Kitchens, and D. L. DeAngelis. 2002. Exploring the effect of drought extent and interval on the Florida Snail Kite: interplay between spatial and temporal scales. Ecological Modelling 149:25-39.

Olson, R. L., and R. A. Sequeira. 1995. An emergent computational approach to the study of ecosystem dynamics. Ecological Modelling 79:95-120.

O'Neill, R. V. 1989. Perspectives in hierarchy and scale. Pages 140-156 in J. Roughgarden, R. M. May, and S. A. Levin, editors. Perspectives in ecological theory. Princeton University Press, Princeton, New Jersey, USA.

O'Neill, R. V., D. L. DeAngelis, J. B. Waide, and T. F. H. Allen. 1986. A hierarchical concept of ecosystems. Princeton University Press, Princeton, New Jersey, USA.

O'Neill, R. V., and A. W. King. 1998. Homage to St. Michael; or, why are there so many books on scale? Pages 3-15 in D. L. Peterson and V. T. Parker, editors. Ecological scale: theory and applications. Columbia University Press, New York, New York, USA.

Paine, R. T., and S. A. Levin. 1981. Intertidal landscapes: disturbance and the dynamics of pattern. Ecological Monographs 51:145-178.

Pascual, M., and S. A. Levin. 1999. From individuals to population densities: searching for the intermediate scale of nontrivial determinism. Ecology 80:2225-2236.

Persson, L., D. Claessen, A. M. De Roos, P. Byström, S. Sjögren, R. Svanbäck, E. Wahlström, and E. Westman. 2004. Cannibalism in a size-structured population: energy extraction and control. Ecological Monographs 74:135-157.

Pihl, L., S. P. Baden, and R. J. Diaz. 1991. Effects of periodic hypoxia on distribution of demersal fish and crustaceans. Marine Biology 108:349-360.

Polis, G. A. 1981. The evolution and dynamics of intraspecific predation. Annual Review of Ecology and Systematics 12: 225-251.

Pressey, R. L., C. J. Humphries, C. R. Margules, R. I. VaneWright, and P. H. Williams. 1993. Beyond opportunism: key principles for systematic reserve selection. Trends in Ecology and Evolution 8:124-128.

Pressey, R. L., H. P. Possingham, and J. R. Day. 1997. Effectiveness of alternative heuristic algorithms for identifying indicative minimum requirements for conservation reserves. Biological Conservation 80:207-219. 
Rasmussen, S., N. A. Baas, B. Mayer, M. Nilsson, and M. W. Olesen. 2001. Ansatz for dynamical hierarchies. Artificial Life 7:329-353.

Roughgarden, J., and F. Smith. 1996. Why fisheries collapse and what to do about it. Proceedings of the National Academy of Sciences (USA) 93:5078-5083.

Rykiel, E. J., Jr. 1996. Testing ecological models: the meaning of validation. Ecological Modelling 90:229-244.

Salthe, S. N. 1985. Evolving hierarchical systems: their structure and representation. Columbia University Press, New York, New York, USA.

Salthe, S. N. 1993. Development and evolution: complexity and change in biology. MIT Press, Cambridge, Massachusetts, USA.

Selberg, C. D., L. A. Eby, and L. B. Crowder. 2001. Hypoxia in the Neuse River estuary: responses of blue crabs and crabbers. North American Journal of Fisheries Management 21:358-366.

Shorrocks, B., and M. Bingley. 1994. Priority effects and species coexistence - experiments with funcal-breeding Drosophila. Journal of Animal Ecology 63:799-806.

Solidoro, C., R. Pastres, D. M. Canu, M. Pellizzato, and R. Rossi. 2000. Modelling the growth of Tapes philippinarum in northern Adriatic lagoons. Marine Ecology Progress Series 199:137-148.

Spitzer, P. M., K. L. Heck, Jr., and J. F. Valentine. 2003. Then and now: a comparison of patterns in blue crab post-larval abundance and post-settlement mortality during the early and late 1990s in the Mobile Bay system. Bulletin of Marine Science 72:435-452.

Stelter, C., M. Reich, V. Grimm, and C. Wissel. 1997. Modelling persistence in dynamic landscapes: lessons from a metapopulation of the grasshopper Bryodema tuberculata. Journal of Animal Ecology 66:508-518.

Stenseth, N. C., A. Shabbar, K.-S. Chan, S. Boutin, E. K. Rueness, D. Ehrich, J. W. Hurrell, O. C. Lingjaerde, and K. S. Jakobsen. 2004. Snow conditions may create an invisible barrier for lynx. Proceedings of the National Academy of Sciences (USA) 101:10632-10634.
Tang, Q. 1985. Modifications of the Ricker stock recruitment model to account for environmentally induced variation in recruitment with particular reference to the blue crab fishery in Chesapeake Bay. Fisheries Research 3:13-21.

Tilman, D., C. L. Lehman, and C. Yin. 1997. Habitat destruction and deterministic extinction in competitive communities. American Naturalist 149:407-435.

Tilman, D., R. M. May, C. L. Lehman, and M. A. Nowak. 1994. Habitat destruction and the extinction dept. Nature 371:65-66.

Uchmanski, J., and V. Grimm. 1996. Individual-based modelling in ecology: what makes the difference. Trends in Ecology and Evolution 11:437-441.

van den Avyle, M. J. 1984. Species profiles: life histories and environmental requirements of coastal fishes and invertebrates (South Atlantic): blue crab. FWS/OBS-82/11. U.S. Fish and Wildlife Service, Lafayette, Louisiana, USA.

Wahlberg, N., T. Klemetti, and I. Hanski. 2002. Dynamic populations in a dynamic landscape: the metapopulation structure of the marsh fritillary butterfly. Ecography 25:224 232.

Wilbur, H. M. 1997. Experimental ecology of food webs: complex systems in temporary ponds. The Robert $\mathrm{H}$. MacArthur Award lecture. Ecology 78:2279-2302.

Wu, J. 1999. Hierarchy and scaling: extrapolating information along a scaling ladder. Canadian Journal of Remote Sensing 25:367-380.

Wu, J., and J. L. David. 2002. A spatially explicit hierarchical approach to modeling complex ecological systems: theory and applications. Ecological Modelling 153:7-26.

Wu, J., and O. L. Loucks. 1995. From balance of nature to hierarchical patch dynamics: a paradigm shift in ecology. Quarterly Review of Biology 70:439-466.

Zeigler, B. P., H. Praehoffer, and T. G. Kim. 2000. Theory of modeling and simulation. Academic Press, New York, New York, USA.

\section{APPENDIX A}

A detailed description of the model (Ecological Archives M076-016-A1).

\section{APPENDIX B}

A summary of the model assessment conducted (Ecological Archives M076-016-A2).

\section{APPENDIX C}

A table of model parameters and additional model results (Ecological Archives M076-016-A3).

\section{APPENDIX D}

A PDF version of Appendices A-C (Ecological Archives M076-016-A4).

\section{APPENDIX E}

MPEG movies of model behaviors under three scenarios (Ecological Archives M076-016-A5). 